\title{
Innovative approaches for cancer treatment: current perspectives and new challenges
}

\author{
Carlotta Pucci $^{1 \mathrm{a}}$ (D), Chiara Martinelli ${ }^{1 \mathrm{~b}}$ (iD) and Gianni Ciofani ${ }^{1,2 c}$ (iD \\ ${ }^{1}$ Smart Bio-Interfaces, Istituto Italiano di Tecnologia, 56025 Pisa, Italy \\ ${ }^{2}$ Department of Mechanical and Aerospace Engineering, Politecnico di Torino, 10129 Torino, Italy \\ ahttps://orcid.org/0000-0002-8976-3711 \\ bhttps://orcid.org/0000-0001-9360-1689 \\ chttps://orcid.org/0000-0003-1192-3647
}

\section{Abstract}

Every year, cancer is responsible for millions of deaths worldwide and, even though much progress has been achieved in medicine, there are still many issues that must be addressed in order to improve cancer therapy. For this reason, oncological research is putting a lot of effort towards finding new and efficient therapies which can alleviate critical side effects caused by conventional treatments. Different technologies are currently under evaluation in clinical trials or have been already introduced into clinical practice. While nanomedicine is contributing to the development of biocompatible materials both for diagnostic and therapeutic purposes, bioengineering of extracellular vesicles and cells derived from patients has allowed designing ad hoc systems and univocal targeting strategies. In this review, we will provide an in-depth analysis of the most innovative advances in basic and applied cancer research.

Keywords: cancer, nanomedicine, extracellular vesicles, targeted therapy, immunotherapy, gene therapy, thermal ablation, radiomics, pathomics

\section{Introduction}

Cancer is one of the main causes of death worldwide, and in the past decade, many research studies have focused on finding new therapies to reduce the side effects caused by conventional therapies.

During cancer progression, tumours become highly heterogeneous, creating a mixed population of cells characterised by different molecular features and diverse responsivity to therapies. This heterogeneity can be appreciated both at spatial and temporal levels and is the key factor responsible for the development of resistant phenotypes promoted by a selective pressure upon treatment administration [1]. Usually, cancer is treated as a global and homogeneous disease and tumours are considered as a whole population of cells. Thus, a deep understanding of these complex phenomena is of fundamental importance in order to design precise and efficient therapies.

Correspondence to: Chiara Martinelli

Email: chiara.martinelli@iit.it

ecancer 2019, 13:961

https://doi.org/10.3332/ecancer.2019.961

Published: 10/09/2019

Received: 21/05/2019

Publication costs for this article were supported by ecancer (UK Charity number 1176307).

Copyright: (c) the authors; licensee ecancermedicalscience. This is an Open Access article distributed under the terms of the Creative Commons Attribution License (http:// creativecommons.org/licenses/by/3.0), which permits unrestricted use, distribution, and reproduction in any medium, provided the original work is properly cited. 
Nanomedicine offers a versatile platform of biocompatible and biodegradable systems that are able to deliver conventional chemotherapeutic drugs in vivo, increasing their bioavailability and concentration around tumour tissues, and improving their release profile [2]. Nanoparticles can be exploited for different applications, ranging from diagnosis to therapy [2].

Recently, extracellular vesicles (EVs), responsible for cancer development, microenvironment modification and required for metastatic progression, have been widely investigated as efficient drug delivery vehicles [3].

Natural antioxidants and many phytochemicals have been recently introduced as anti-cancer adjuvant therapies due to their anti-proliferative and pro-apoptotic properties [4, 5].

Targeted therapy is another branch of cancer therapy aiming at targeting a specific site, such as tumour vasculature or intracellular organelles, leaving the surroundings unaffected. This enormously increases the specificity of the treatment, reducing its drawbacks [6].

Another promising opportunity relies on gene therapy and expression of genes triggering apoptosis [7] and wild type tumour suppressors [8], or the targeted silencing mediated by siRNAs, currently under evaluation in many clinical trials worldwide [9].

Thermal ablation of tumours and magnetic hyperthermia are opening new opportunities for precision medicine, making the treatment localised in very narrow and precise areas. These methods could be a potential substitute for more invasive practices, such as surgery [10, 11].

Furthermore, new fields such as radiomics and pathomics are contributing to the development of innovative approaches for collecting big amounts of data and elaborate new therapeutic strategies [12,13] and predict accurate responses, clinical outcome and cancer recurrence [14-16].

Taken all together, these strategies will be able to provide the best personalised therapies for cancer patients, highlighting the importance of combining multiple disciplines to get the best outcome.

In this review, we will provide a general overview of the most advanced basic and applied cancer therapies, as well as newly proposed methods that are currently under investigation at the research stage that should overcome the limitation of conventional therapies; different approaches to cancer diagnosis and therapy and their current status in the clinical context will be discussed, underlining their impact as innovative anti-cancer strategies.

\section{Nanomedicine}

Nanoparticles are small systems (1-1,000 nm in size) with peculiar physicochemical properties due to their size and high surface-to-volume ratio [17]. Biocompatible nanoparticles are used in cancer medicine to overcome some of the issues related to conventional therapies, such as the low specificity and bioavailability of drugs or contrast agents [2]. Therefore, encapsulation of the active agents in nanoparticles will increase their solubility/biocompatibility, their stability in bodily fluids and retention time in the tumour vasculature [18-20]. Furthermore, nanoparticles can be engineered to be extremely selective for a precise target [21, 22] (see the "Targeted therapy and immunotherapy" section) and to release the drug in a controlled way by responding to a specific stimulus [18, 23-25]. This is the case of ThermoDox, a liposomal formulation that can release doxorubicin as a response to an increment of temperature [26].

Inorganic nanoparticles are generally used as contrast agents for diagnosis purposes. Among them, quantum dots are small light-emitting semiconductor nanocrystals with peculiar electronic and optical properties, which make them highly fluorescent, resistant to photobleaching and sensitive for detection and imaging purposes [27]. Combined with active ingredients, they can be promising tools for theranostic applications [27]. In a recent study, quantum dots coated with poly(ethylene glycol) (PEG) were conjugated to anti-HER2 antibody and localised in specific tumour cells [28].

Superparamagnetic iron oxide nanoparticles (SPIONs) are usually exploited as contrast agents in magnetic resonance imaging (MRI) because they interact with magnetic fields [29, 30]. Five types of SPIONs have been tested for MRI: ferumoxides (Feridex in the US, Endorem in Europe), ferucarbotran (Resovist), ferucarbotran C (Supravist, SHU 555 C), ferumoxtran-10 (Combidex) and NC100150 (Clariscan). Ferucarbotran is currently available in few countries, while the others have been removed from the market [25]. SPIONs have also been studied for 
cancer treatment by magnetic hyperthermia (see the "Thermal ablation and magnetic hyperthermia" section), and a formulation of iron oxide coated with aminosilane called Nanotherm has been already approved for the treatment of glioblastoma [31].

Gold nanoparticles have raised interest because of their optical and electrical properties and low toxicity [32-34]. They are mainly used as contrast agents for X-ray imaging, computed tomography [25], photoacoustic imaging [35] and photodynamic therapy [36]. A nanoshell made of a silica core and a gold shell coated with PEG was approved by the Food and Drug Administration (FDA) in 2012 and commercialised as AuroShell (Nanospectra) for the treatment of breast cancer by photodynamic therapy [25].

Organic nanoparticles are mainly used as delivery systems for drugs. Liposomes and micelles are both made of phospholipids, but they differ in their morphology. Liposomes are spherical particles having at least one lipid bilayer, resembling the structure of cell membranes. They are mainly used to encapsulate hydrophilic drugs in their aqueous core, but hydrophobic drugs can also be accommodated in the bilayer or chemically attached to the particles [37]. Micelles, instead, own a hydrophobic core that can encapsulate hydrophobic drugs [38]. Doxil, doxorubicin-loaded PEGylated liposomes, were the first nanoparticles approved by the FDA in 1995 to treat AIDS-associated Kaposi's sarcoma [39]. This formulation drastically reduces doxorubicin side effects. Since then, other liposomal formulations have been approved by the FDA for cancer therapy, such as Myocet and DaunoXome [40-42]. Polymeric nanoparticles are made of biocompatible or natural polymers, such as poly(lactide-co-glycolide), poly( $\varepsilon$-caprolactone), chitosan, alginate and albumin [43]. Some formulations have already been accepted by the FDA, such as Abraxane (albumin-paclitaxel particles for the treatment of metastatic breast cancer and pancreatic ductal adenocarcinoma) and Ontak (an engineered protein combining interleukin-2 and diphtheria toxins for the treatment of non-Hodgkin's peripheral T-cell lymphomas).

As well as these systems, which have been either accepted or are under clinical investigation, it is worth mentioning some new nanoparticles currently undergoing testing at the research level, which should improve treatment performance. For example, solid lipid nanoparticles, made of lipids that are solid at body temperature [44], and fabricated to load hydrophobic drugs [45] have been demonstrated to give a higher drug stability and prolonged release compared to other systems; however, the encapsulation efficiency is often low because of their high crystallinity [46]. To overcome this issue, one or more lipids, liquid at room temperature (like oleic acid, for example), are included in the formulation [47]. Lipid nanoparticles are good candidates for brain tumour therapy as they are able to cross the blood-brain barrier (BBB) [48]. A recent work showed that lipid nanoparticles loaded with SPIONs and temozolomide are efficient to treat glioblastoma since they combine the effect of the conventional chemotherapy and hyperthermia $[49,50]$. Dendrimers are another family of nanoparticles composed of polymers with a repetitive branched structure and characterised by a globular morphology [51, 52]. Their architecture can be easily controlled, making their structure extremely versatile for many applications. For example, some recent studies show that poly-L-lysine (PLL) dendrimers loaded with doxorubicin induce anti-angiogenic responses in in vivo tumour models [53]. Currently, there is only one clinical trial for a formulation named ImDendrim based on a dendrimer and on a rhenium complex coupled to an imidazolium ligand, for the treatment of inoperable liver cancers that do not respond to conventional therapies [54].

\section{Extracellular vesicles for cancer diagnosis and therapy}

EVs are classified in two categories based on their biogenesis. Specifically, exosomes are small vesicles of around 30-150 nm originated from endosomes in physiological and pathological conditions and released by a fusion of multivesicular bodies (MVBs) to the cell membrane $[55,56]$, while shed microvesicles (sMVs), with a typical size of 50-1,300 nm, are present in almost any extracellular bodily fluid and are responsible for the exchange of molecular materials between cells [57, 58]. Exosomes are involved in cancer development and spreading $[3,59,60]$, in the bidirectional communication between tumour cells and surrounding tissues, and in the construction of the microenvironment needed for pre-metastatic niche establishment and metastatic progression [61]. Hence, circulating vesicles are clinically relevant in cancer diagnosis, prognosis and follow up. Exosomes are actually recognised as valid diagnostic tools, but they can also be isolated and exploited as anti-cancer vaccines or nanosized drug carriers in cancer therapy [62].

Nowadays, one of the main issues in cancer diagnosis is the early identification of biomarkers by non-invasive techniques. Obtaining a significant amount of information, before and during tumour treatment, should allow the monitoring of cancer progression and the efficacy of therapeutic regimens. Liquid biopsies to detect circulating tumour cells, RNAs, DNAs and exosomes have been used as indicators for 
personalised medicine [63]. In recent years, exosomes detection has been validated as a reliable tool for preclinical practice in different cancer types [64], thanks to the identification of their content: double-stranded DNA (dsDNA) [65, 66], messenger RNA (mRNA), micro RNA (miRNA), long non-coding RNA (IncRNA) [67], proteins and lipids [68]. DsDNA has been detected in exosomes isolated from plasma and serum of different cancer cell types, and mutated genes involved in tumorigenesis, such as mutated KRAS and TP53 [69, 70], have been identified as disease predictors. Similarly, exosomal AR-V7 mRNA has been used as a prognostic marker of resistance to hormonal therapy in metastatic prostate cancer patients [71]. Gene expression profiling of multiple RNAs from urinary exosomes has been adopted as an efficient diagnostic tool [72]. LncRNAs isolated from serum exosomes have been exploited for disease prognosis in colorectal cancer patients [73], and multiple miRNAs allow one to distinguish between different lung cancer subtypes [74]. GPC1-positive exosomes have been employed to detect pancreatic cancer [75], while circulating exosomal macrophage migration inhibitory factor (MIF) was able to predict liver metastasis onset [76]. Finally, multiple lipids present in urinary exosomes have been approved as prostate cancer indicators [77]. Due to the high variability of patient classes and sample size, and in order to obtain clinically significant results for a fast and effective diagnosis, huge investments in exosome research will be required in the near future.

Exosomes could also be exploited as natural, biocompatible and low immunogenic nanocarriers for drug delivery in cancer therapy. They can be passively loaded by mixing purified vesicles with small drugs [78-82], or actively loaded by means of laboratory techniques, such as electroporation and sonication [83, 84]. Superparamagnetic nanoparticles conjugated to transferrin have been tested for the isolation of exosomes expressing transferrin receptor from mice blood. After incubation with doxorubicin, they have been used to target liver cancer cells in response to external magnetic fields, inhibiting cell growth both in vitro and in vivo [80]. Kim et al. [83] engineered mouse macrophagederived exosomes with aminoethyl anisamide-PEG to target sigma receptor, overexpressed in lung cancer cells and passively loaded them with paclitaxel. These systems acted as targeting agents able to suppress metastatic growth in vivo.

Three clinical trials with loaded exosomes are currently ongoing for the treatment of different tumours [85-87]: a phase I trial is evaluating the ability of exosomes to deliver curcumin to normal and colon cancer tissues [85]; a phase II trial is investigating the in vivo performance of autologous tumour cell-derived microparticles carrying methotrexate in lung cancer patients [86] and a clinical inquiry is focusing on autologous erythrocyte-derived microparticles loaded with methotrexate for gastric, colorectal and ovarian cancer treatment [87].

Recently, new strategies to produce ad hoc exosomes have been developed. Cells releasing exosomes have been genetically engineered to overexpress specific macromolecules, or modified to release exosomes with particular targeting molecules [88-90].

Exosomes derived from different cancer cells have already been exploited as cancer vaccines. Autologous dendritic cell-derived exosomes with improved immunostimulatory function have been tested in a phase II clinical trial for the activation of CD8 $8^{+} \mathrm{T}$ cells [91] in non-small cell lung cancer (NSCLC) patients, observing disease stabilisation and a better overall survival [92]. In a phase I trial, ascites-derived exosomes supplemented with granulocyte-macrophage colony stimulating factor (GM-CSF) have been administered to colorectal cancer patients, soliciting a tumour-specific immune response [93].

Many issues related to exosomes clinical translation remain open and are mostly connected to the definition of preclinical procedures for isolation, quantification, storage and standard protocols for drug loading. It is becoming even more necessary to distinguish between tumour and healthy blood cell-derived vesicles to characterise their post-isolation half-life and to perform standard content analyses. For these purposes, innovative approaches and technologies have been set up, such as microarrays and specific monoclonal antibodies and RNA markers amplification strategies [94].

\section{Natural antioxidants in cancer therapy}

Every day, the human body undergoes several exogenous insults, such as ultraviolet (UV) rays, air pollution and tobacco smoke, which result in the production of reactive species, especially oxidants and free radicals, responsible for the onset of many diseases, including cancer. These molecules can also be produced as a consequence of clinical administration of drugs, but they are also naturally created inside our cells and tissues by mitochondria and peroxisomes, and from macrophages metabolism, during normal physiological aerobic processes.

Oxidative stress and radical oxygen species are able to damage DNA (genetic alterations, DNA double strand breaks and chromosomal aberrations [95, 96]) and other bio-macromolecules [97], such as lipids (membrane peroxidation and necrosis [98]) and proteins (significantly changing the regulation of transcription factors and, as a consequence, of essential metabolic pathways [99]). 
The protective mechanisms our body has developed against these molecules are sometimes insufficient to counteract the huge damages produced. Recently, in addition to research into the roles of the physiological enzymes superoxide dismutase (SOD), catalase (CAT) and glutathione peroxidase (GP), natural antioxidants such as vitamins, polyphenols and plant-derived bioactive compounds are being studied in order to introduce them as preventive agents and potential therapeutic drugs [100, 101]. These molecules have anti-inflammatory and anti-oxidant properties and are found in many vegetables and spices [102]. Vitamins, alkaloids, flavonoids, carotenoids, curcumin, berberine, quercetin and many other compounds have been screened in vitro and tested in vivo, displaying appreciable anti-proliferative and pro-apoptotic properties, and have been introduced as complementary therapies for cancer [4, 5, 103].

Despite the advantages of using natural drugs, their translation into clinical practice remains difficult due to their limited bioavailability and/ or toxicity. Curcumin, a polyphenolic compound extracted from turmeric (Curcuma longa), is a traditional Southeast Asian remedy with antiinflammatory, anti-oxidant and chemopreventive and therapeutic activities [104]. It has been shown to have cytotoxic effects in different kinds of tumours, such as brain, lung, leukaemia, pancreatic and hepatocellular carcinoma [105, 106], with no adverse effects in normal cells at the effective therapeutic doses [107]. Curcumin can modulate a plethora of cellular mechanisms [108, 109]; however, its biological properties, and as a consequence, the treatment duration and the efficient therapeutic doses, have not been completely elucidated yet. This molecule is highly lipophilic, poorly soluble in water and not very stable [110]. Different strategies and specific carriers, such as liposomes and micelles [111, 112], have been developed to improve its bioavailability. Currently, 24 clinical trials involving curcumin are ongoing and 23 have been already completed [113].

Berberine is an alkaloid compound extracted from different plants, such as Berberis. Recently, it has been demonstrated to be effective against different tumours and to act as a chemopreventive agent, modulating many signalling pathways [114, 115]. Like curcumin, it is poorly soluble in water; therefore, different nanotechnological strategies have been developed to facilitate its delivery across cell membranes [116-119]; six clinical trials are open and one has been completed [120].

Quercetin, a polyphenolic flavonoid found in fruits and vegetable, has been proven to be effective to treat several tumours, such as lung, prostate, liver, colon and breast cancers [121-123], by binding cellular receptors and interfering with many signalling pathways [124]. Interestingly, it has been shown to be effective also in combination with chemotherapeutic agents [125]. Presently, seven clinical trials are open and four have been completed [126].

\section{Targeted therapy and immunotherapy}

One of the main problems of conventional cancer therapy is the low specificity of chemotherapeutic drugs for cancer cells. In fact, most drugs act both on healthy and diseased tissues, generating severe side effects. Researchers are putting a lot of effort into finding a way to target only the desired site. Nanoparticles have raised great interest for their tendency to accumulate more in tumour tissues due to the enhanced permeability and retention effect (EPR) [127]. This process, called passive targeting, relies on the small size of nanoparticles and the leaky vasculature and impaired lymphatic drainage of neoplastic tissues [6]. Passive targeting, however, is difficult to control and can induce multidrug resistance (MDR) [128]. Active targeting, on the other hand, enhances the uptake by tumour cells by targeting specific receptors that are overexpressed on them [129, 130]. Nanoparticles, for example, can be functionalized with ligands that univocally bind particular cells or subcellular sites [6]. Several kinds of ligands can be used, such as small molecules, peptides, proteins, aptamers and antibodies.

Folic acid and biotin are small molecules, whose receptors are overexpressed in tumour tissues. Several nanocarriers have been functionalized with folic acid to target ovarian and endometrial cancers [131]: folic acid-conjugated polyethylene glycol-poly(lactic-co-glycolic acid) nanoparticles delivering docetaxel increased drug cellular uptake by human cervical carcinoma cells [132]. Small ligands are cheap and can be linked to nanoparticles by simple conjugation chemistry [133, 134].

Different kinds of small peptides and proteins are also effective in active targeting. Angiopep-2 is a peptide that has raised great interest in the treatment of brain cancer [135], because it binds to low-density lipoprotein receptor-related protein-1 (LRP1) of endothelial cells in the BBB, and it is also overexpressed in glioblastoma cancer cells [136]. Bombesin peptide conjugated to poly(lactic-co-glycolic acid) (PLGA) nanoparticles loaded with docetaxel was used to target the gastrin-releasing peptide receptor, overexpressed on cell surface of prostate, breast, ovarian, pancreatic and colorectal cancer cells $[137,138]$. Transferrin is a serum glycoprotein overexpressed on many solid tumours, especially on glioblastoma multiforme cells [139], and on epithelial cells of the BBB [6, 140]. Transferrin-conjugated chitosan-PEG nanoparticles delivering paclitaxel exhibited a higher cytotoxicity towards transferrin-overexpressing human non-small cell lung cancer cells (NSCLCs) (HOP-62) [141]. 
Aptamers are small synthetic single-stranded RNA or DNA oligonucleotides folded into specific shapes that make them capable of binding specific targets [142]. Farokhzad et al. [143] reported that the use of A10 RNA aptamer conjugated to docetaxel-loaded nanoparticles significantly enhances in vitro cytotoxicity. The same aptamer has been also used to prepare quantum dot-doxorubicin conjugates [144].

Antibodies are currently the most exploited ligands for active targeting. These proteins have a typical ' $Y$ ' shape, where the two arms are responsible for the selective interaction with the antigen [145]. Antibodies can be used as immunoconjugates, when conjugated to a drug or nanoparticle, or naked. In the first case, their function is mainly to target a specific antigen overexpressed on cancer cells. Antibodies used for this purpose include those ones that bind to the human epidermal growth factor receptor 2 (HER2), the epidermal growth factor receptor (EGFR), the transferrin receptor (TfR) and the prostate-specific membrane antigen (PSMA) [6]. Rapamycin-PLGA nanoparticle conjugated to EGFR antibody exhibited higher cellular uptake by human breast adenocarcinoma cells (MCF-7), with enhanced apoptotic activity [146]. Loperamide-loaded human serum albumin nanoparticles conjugated to antibodies that specifically bind transferrin receptor successfully crossed the BBB and delivered the drug to the desired site [147].

Naked antibodies or immunoconjugates can also be used in immunotherapy, which is a cancer treatment that aims at stimulating or restoring the immune system of the patient against cancer cells [148]. Antibodies can act as markers for cancer cells to make them more vulnerable to the immune system response (non-specific immune stimulation), or as inhibitors for immune checkpoint proteins on cancer cell surface, that can modulate the action of T-cells [148]. Several antibodies have been already tested and accepted by FDA for immunotherapy, such as rituximab (1997, [149]), ibritumomab tiuxetan (2002, [150]), trastuzumab emtansine (2013, [151]), nivolumab (2014, [152]) and pembrolizumab (2014, [153]).

Immunotherapy can be achieved by another strategy called adoptive cell transfer (ACT) and it consists of isolating T-lymphocytes (T-cells) with the highest activity against cancer directly from the patient's blood, expanding them ex vivo, and reinfusing them again into the patient [154]. Autologous T-cells can be genetically engineered in vitro to express a chimaeric antigen receptor (CAR), which makes them more specific against cancer cell antigens [148]. Different CARs can be designed to be directed against a certain cancer antigen. The genetic modification of T-cells can be achieved by different methods such as viral transduction, non-viral methods like DNA-based transposons, CRISPR/Cas9 or other plasmid DNA and mRNA transfer techniques (i.e., electroporation, encapsulation in nanoparticles) [155]. ACT protocols have been already adopted in clinical practice for advanced or recurrent acute lymphoblastic leukaemia and for some aggressive forms of non-Hodgkin's lymphoma [148]. For example, it has been shown that the treatment of end-stage patients affected by acute lymphocytic leukaemia with CAR T-cells led to a full recovery in up to $92 \%$ of patients [155]. Despite these very promising results, much research is currently devoted to understanding the long-term side effects of CAR T-cell therapies and their fate within tumours, and to improving CAR T-cell expansion technologies.

\section{Gene therapy for cancer treatment}

Gene therapy is intended as the introduction of a normal copy of a defective gene in the genome in order to cure specific diseases [156]. The first application dates back to 1990 when a retroviral vector was exploited to deliver the adenosine deaminase (ADA) gene to T-cells in patients with severe combined immunodeficiency (SCID) [157]. Further research demonstrated that gene therapy could be applied in many human rare and chronic disorders and, most importantly, in cancer treatment. Approximately 2,900 gene therapy clinical trials are currently ongoing, $66.6 \%$ of which are related to cancer [158]. Different strategies are under evaluation for cancer gene therapy: 1) expression of proapoptotic [159, 160] and chemo-sensitising genes [4]; 2) expression of wild type tumour suppressor genes [5]; 3) expression of genes able to solicit specific antitumour immune responses and 4) targeted silencing of oncogenes.

One approach relied on thymidine kinase (TK) gene delivery, followed by administration of prodrug ganciclovir to activate its expression and induce specific cytotoxicity [161]. This has been clinically translated for the treatment of prostate cancer and glioma [162-164]. In recent decades, different vectors carrying the p53 tumour suppressor gene have been evaluated for clinical applications. ONYX-015 has been tested in NSCLC patients and gave a high response rate when administered alone or together with chemotherapy [165]. Gendicine, a recombinant adenovirus carrying wild-type p53 in head and neck squamous cell cancer had a similar success, inducing complete disease regression when combined with radiotherapy [166]. 
Despite many achievements, there are still some challenges to face when dealing with gene therapy, such as the selection of the right conditions for optimal expression levels and the choice of the best delivery system to univocally target cancer cells. Gene therapy also presents some drawbacks linked to genome integration, limited efficacy in specific subsets of patients and high chances of being neutralised by the immune system. Therefore, particular interest has been elicited by targeted gene silencing approaches.

RNA interference (RNAi) has been recently established as an efficient technology both for basic research and medical translation. Small interfering RNAs (siRNAs) consist of double-stranded RNAs [167] able to produce targeted gene silencing. This process is intracellularly mediated by the RNA-induced silencing complex (RISC), responsible for cleaving the messenger RNA (mRNA), thus leading to interference with protein synthesis [168]. This physiological mechanism has been demonstrated in many eukaryotes, including animals. A few years after RNAi discovery, the first clinical application for wet-age related macular degeneration treatment entered phase I clinical trial [169]. Since cancer is triggered by precise molecular mechanisms, siRNAs can be rationally designed to block desired targets responsible for cell proliferation and metastatic invasion. This strategy relies on siRNA-mediated gene silencing of anti-apoptotic proteins [170], transcription factors (i.e., c-myc gene) [171, 172] or cancer mutated genes (i.e., K-RAS) [173]. Most of the clinical trials currently ongoing are based on local administration of siRNA oligonucleotides in a specific tissue/organ or on systemic delivery throughout the entire body [9, 174]. Using siRNA-based drugs has several advantages: 1) safety, since they do not interact with the genome; 2) high efficacy, because only small amounts can produce a dramatic gene downregulation; 3) possibility of being designed for any specific target; 4) fewer side effects when compared to conventional therapies and 5) low costs of production $[175,176]$. However, siRNAs are relatively unstable in vivo and can be phagocytosed during blood circulation, excreted by renal filtration, or undergo enzymatic degradation [177]. Occasionally, they can induce off-target effects [178] or elicit innate immune responses, followed by specific inflammation $[179,180]$. Since naked siRNAs are negatively charged hydrophilic molecules, they cannot spontaneously cross cell membranes. Consequently, different delivery strategies are currently under study, such as chemical modification, encapsulation into lipid or polymeric carriers or conjugation with organic molecules (polymers, peptides, lipids, antibodies, small molecules [181], for efficient targeting [182, 183]). Chemical modifications include the insertion of a phosphorothioate at 3' end to reduce exonuclease degradation [184], the introduction of 2' O-methyl group to obtain longer half-life in plasma [185] and the modification by 2,4-dinitrophenol to favour membrane permeability [186]. Nevertheless, the degradation of modified siRNAs often elicits cytotoxic effects; therefore, it is preferable to design ad hoc nanocarriers.

Different cationic lipid nanoparticles, such as liposomes, micelles and solid lipid nanoparticles [183], have been exploited for siRNA loading. Cationic liposomes interact with negatively charged nucleic acids, which can be easily transfected by simple electrostatic interactions $[187,188]$. They can be constituted by 1,2-dioleoyl-3-trimethylammonium propane (DOTAP) and N-\{1-(2,3-dioleoyloxy) propyl]-N,N,Ntrimethylammonium methyl sulphate (DOTMA) [189]. A theranostic agent consisting of an anticancer survivin siRNA entrapped in PEGylated liposomes has been developed to achieve simultaneous localisation inside tumour cells by means of entrapped MR agents and fluorophores and reduction of proliferation in vivo [190].

Neutral liposomes based on 1,2-dioleoyl-sn-glycero-3-phosphatidylcholine (DOPC) have shown high efficacy in mice models of ovarian carcinoma and colorectal cancer [191, 192]. A phase I clinical trial is currently recruiting patients for evaluating the safety of siRNA-EphA2DOPC when administered to patients with advanced and recurrent cancer [193].

Stable nucleic acid lipid particles (SNALPs) have been evaluated in non-human primates [194]. SiRNAs have been encapsulated in a mixture of cationic lipids coated with a shell of polyethylene glycol (PEG) [195]. SNALPs entered a phase I clinical trial in patients affected by advanced solid tumours with liver involvement [196] and a phase I/II trial for treating neuroendocrine tumours and adrenocortical carcinoma patients refractory to standard therapy [197].

SiRNAs can be condensed in cationic polymers such as chitosan, cyclodextrin and polyethylenimine (PEI). Chitosan is a natural polysaccharide that, due to its cationic charge, has been exploited as carrier for nucleic acids in vitro and in vivo [198]. Specifically, a targeted siRNA has been delivered in mice xenografts of breast cancer [199]. Cyclodextrin polymers coated with PEG, conjugated with human transferrin and carrying a siRNA called CALAA-01, inhibit tumour growth by reducing the expression of M2 subunit of ribonucleotide reductase (R2), and have entered a phase I clinical trial [200]. PEl is able to form small cationic nanoparticles containing siRNAs and it has been exploited as antitumoural, upon loading with HER-2 receptor-specific siRNA [201]. A phase II clinical trial is presently starting to evaluate siG12D LODER directed to mutated KRAS oncogene and encapsulated into a biodegradable polymeric matrix for locally treating advanced pancreatic cancer patients in combination with chemotherapy [202]. 
SiRNAs may be conjugated to peptides, antibodies and aptamers in order to improve their stability during circulation and to enhance cellular uptake [203]. A success is represented by siRNAs targeting PSMA, overexpressed in this type of cancer [204].

The introduction of nanocarriers has largely improved siRNAs stability, pharmacokinetics and biodistribution properties, and the targeting specificity $[205,206]$. Smart nanomaterials responsive to external (i.e., magnetic field, ultrasounds) and tumour-specific stimuli (i.e., acidic pH, redox conditions) are currently under the development for controlled release and reduction of undesired negative effects [207, 208]. Nanocarriers delivering siRNAs undergo a series of $\mathrm{pH}$ variations from blood circulation to intracellular environment and, for this reason, many $\mathrm{pH}$ responsive materials have been designed to favour cargo release under specific pH conditions [209]. Poly(allylamine) phosphate nanocarriers, stable at physiological $\mathrm{pH}$, have been developed to release siRNAs in the cytoplasm after disassembly at low endosomal pH [210].

Although there have been many successes, some questions remain open and make the clinical translation of the siRNA-based approach very challenging, such as the correct doses to be delivered to patients and the many variabilities observed between individuals and different stages of disease. Further research towards controlled release to reach only specific targets, and the set-up of the best personalised therapy for cancer patients will be necessary in the near future.

\section{Thermal ablation and magnetic hyperthermia}

Thermal ablation of tumours includes a series of techniques that exploit heat (hyperthermia) or cold (hypothermia) to destroy neoplastic tissues [13]. It is known that cell necrosis occurs at temperatures lower than $-40^{\circ} \mathrm{C}$ or higher than $60^{\circ} \mathrm{C}$. Long exposures to temperatures between $41^{\circ} \mathrm{C}$ and $55^{\circ} \mathrm{C}$ are also effective for tumour cell damage. Moreover, it has been shown that cancer cells are more sensitive to high temperatures than healthy ones [211].

Hypothermic ablation is due to the formation of ice crystals upon cooling, which destroy cell membranes and finally kill cells. Argon gas is the preferred cooling agent because it can cool down the surrounding tissues to $-160^{\circ} \mathrm{C}$. Also, gases at their critical point, such as nitrogen, can be exploited since they have a higher heat capacity than argon. However, the technology to control and direct them is not well developed yet [10].

Hyperthermic ablation currently comprises radiofrequency (RF), microwave and laser ablation [10].

RF ablation is the most used in clinics, because it is effective and safe [212]. An alternated current of RF waves is applied to a target zone by an insulated electrode tip, while a second electrode, needed to close the circuit, is placed on the skin surface [10]. The interaction with the current causes the oscillation of ions in the extracellular fluid, which, in turns, produces heat. The more conductive the medium, the more effective the process. For this reason, RF ablation works very well in the liver and in other areas with a high content of water and ions, whereas it has a poor effect in lungs [10]. Moreover, the efficiency of the treatment decreases with the size of the lesion, giving the best results for areas not larger than $3 \mathrm{~cm}^{2}[213,214]$.

Microwave ablation is based on the electromagnetic interaction between microwaves and the polar molecules in tissues, like water, that causes their oscillation and the consequent increase in temperature. Unlike the electrical current in RF ablation, microwaves can propagate through any kind of tissue $[215,216]$, and this allows high temperatures to be reached in a short amount of time, to have a deeper penetration and to treat larger areas of tumours [217].

Laser therapy exploits the properties of laser beams of being very narrow and extremely focused at a specific wavelength. This makes the treatment very powerful and precise, thus a promising alternative to conventional surgery [218]. The absorption of the light emitted by the laser results in the heating and subsequent damage of the treated area [219]. Depending on the specific application, different kinds of lasers can be used. Neodymium:yttrium-aluminium-garnet (Nd:YAG) lasers (wavelength of $1064 \mathrm{~nm}$ ) and diode lasers (wavelength of $800-900 \mathrm{~nm}$ ) are used to treat internal organs, since they have a penetration depth up to $10 \mathrm{~cm}$ [218]. Conversely, $\mathrm{CO}_{2}$ lasers (10,600 nm), with a penetration depth of $10 \mu \mathrm{m}$ up to $1 \mathrm{~mm}$ maximum are used for superficial treatments. Laser therapy is receiving a lot of attention in research because of its advantages compared to other ablation techniques, such as a higher efficacy, safety and precision, and a shorter treatment session needed to achieve the same results [220, 221]. Moreover, the fibres to transmit laser light are compatible with MRI, allowing for a precise 
measure of the temperature and the thermal dose [222]. However, there are still some limitations to overcome, such as the need of a very skilled operator to place the fibre in the correct position [218].

Finally, a new way to heat tumour tissues, currently under study, is through magnetic hyperthermia. This technique exploits superparamagnetic or ferromagnetic nanoparticles that can generate heat after stimulation with an alternating magnetic field. The most studied systems in nanomedicine are SPIONs [11]. The production of heat, in this case, is due to the alignment of magnetic domains in the particles when the magnetic field is applied, and the subsequent relaxation processes (Brownian and/or Neel relaxations) during which heat is released, when the magnetic field is removed and the magnetisation of the particles reverts to zero [223]. Magnetic hyperthermia can reach any area of the body and SPIONs can also act as MRI contrast agents to follow their correct localisation before the stimulation. The particles can be coated with biocompatible polymers and/or lipid and functionalized with specific ligands to impart targeting properties [224]. As already mentioned, until now, just a formulation of 15-nm iron oxide nanoparticles coated with aminosilane (Nanotherm) obtained approval for the treatment of glioblastoma [31]. SPIONs have also been successfully encapsulated in lipid nanocarriers together with a chemotherapeutic agent to combine chemotherapy and hyperthermia $[49,50]$.

\section{Recent innovations in cancer therapy: Radiomics and pathomics}

Efficient cancer therapy currently relies on surgery and, in approximately $50 \%$ of patients, on radiotherapy, that can be delivered by using an external beam source or by inserting locally a radioactive source (in this case, the approach is named brachytherapy), thus obtaining focused irradiation. Currently, localisation of the beam is facilitated by image-guided radiotherapy (IGRT), where images of the patient are acquired during the treatment allowing the best amount of radiation to be set. Thanks to the introduction of intensity-modulated radiotherapy (IMRT), radiation fields of different intensities can be created, helping to reduce doses received by healthy tissues and thus limiting adverse side effects. Finally, by means of stereotactic ablative radiotherapy (SABR), it has become feasible to convey an ablative dose of radiation only to a small target volume, significantly reducing undesired toxicity [225].

Unfortunately, radioresistance can arise during treatment, lowering its efficacy. This has been linked to mitochondrial defects; thus, targeting specific functions have proven to be helpful in restoring anti-cancer effects [226]. A recent study has shown, for example, that radioresistance in an oesophageal adenocarcinoma model is linked to an abnormal structure and size of mitochondria, and the measurement of the energy metabolism in patients has allowed discrimination between treatment resistant and sensitive patients [227]. Targeting mitochondria with small molecules acting as radiosensitizers is being investigated for gastrointestinal cancer therapy [228].

Cancer is a complex disease and its successful treatment requires huge efforts in order to merge the plethora of information acquired during diagnostic and therapeutic procedures. The ability to link the data collected from medical images and molecular investigations has allowed an overview to be obtained of the whole tridimensional volume of the tumour by non-invasive imaging techniques. This matches with the main aim of precision medicine, which is to minimise therapy-related side effects, while optimising its efficacy to achieve the best individualised therapy [229].

Radiomics and pathomics are two promising and innovative fields based on accumulating quantitative image features from radiology and pathology screenings as therapeutic and prognostic indicators of disease outcome [12, 13, 230]. Many artificial intelligence technologies, such as machine learning application, have been introduced to manage and elaborate the massive amount of collected datasets and to accurately predict the treatment efficacy, the clinical outcome and the disease recurrence. Prediction of the treatment response can help in finding an ad hoc adaptation for the best prognosis and outcome. Nowadays, personalised medicine requires an integrated interpretation of the results obtained by multiple diagnostic approaches, and biomedical images are crucial to provide real-time monitoring of disease progression, being strictly correlated to cancer molecular characterisation.

Radiomics is intended as the high throughput quantification of tumour properties obtained from the analysis of medical images [14, 15, 231]. Pathomics, on the other side, relies on generation and characterisation of high-resolution tissue images [16, 232, 233]. Many studies are focusing on the development of new techniques for image analysis in order to extrapolate information by quantification and disease characterisation [234, 235]. Flexible databases are required to manage big volumes of data coming from gene expression, histology, 3D tissue reconstruction (MRI) and metabolic features (positron emission tomography, PET) in order to identify disease phenotypes [236, 237]. 
Currently, there is an urgent need to define univocal data acquisition guidelines. Some initiatives to establish standardised procedures and facilitate clinical translation have been already undertaken, such as quantitative imaging network [238] or the German National Cohort Consortium [239]. Precise description of the parameters required for image acquisition and for the creation and use of computational and statistical methods are necessary to set robust protocols for the generation of models in radiation therapy. According to the US National Library of Medicine, approximately 50 clinical trials involving radiomics are currently recruiting patients, and a few have already been completed [240].

\section{Conclusions and future perspectives}

In recent years, research into cancer medicine has taken remarkable steps towards more effective, precise and less invasive cancer treatments (Figure 1). While nanomedicine, combined with targeted therapy, helped improving the biodistribution of new or already tested chemotherapeutic agents around the specific tissue to be treated, other strategies, such as gene therapy, siRNAs delivery, immunotherapy and antioxidant molecules, offer new possibilities to cancer patients. On the other hand, thermal ablation and magnetic hyperthermia are promising alternatives to tumour resection. Finally, radiomics and pathomics approaches help the management of big data sets from cancer patients to improve prognosis and outcome.

At the moment, the most frequent entries concerning cancer therapies in the database of clinical trials (www.clinicaltrials.gov) involve the terms targeted therapy, immunotherapy and gene therapy, highlighting that these are the most popular methodologies under investigation, especially because, as already mentioned before, they have been shown to be very promising and effective (Figure 2A). However, Figure 2B shows that the clinical trials started in the past decade on different therapies mentioned in this review (except for liposomes-based therapies) have increased in number, showing how the interest on these new approaches is quickly growing in order to replace and/or improve conventional therapies. In particular, radiomics, immunotherapy and exosomes are the entries whose number has increased the most in the last 10 years.

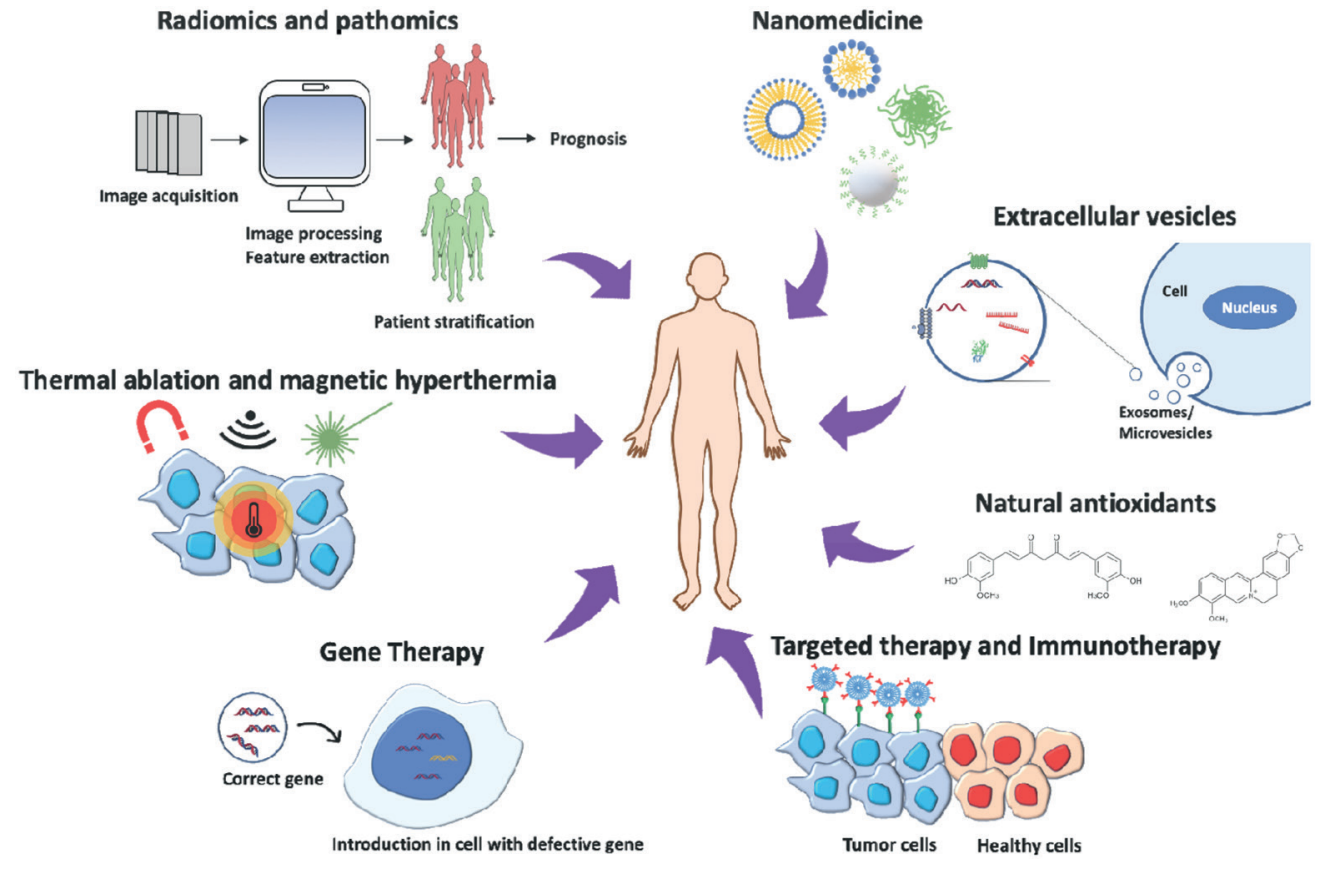

Figure 1. Cancer therapy approaches: The image represents the most innovative strategies to treat cancer, combining different disciplines to obtain the most efficient and personalised therapy for patients. 
The current scenario for cancer research is wide, offering many possibilities for the constant improvement of treatment, considering not only patient recovery but also caring for their well-being during therapy. As summarised in Table 1, these new approaches offer many advantages compared to conventional therapies. However, some disadvantages still have to be overcome to improve their performances. Much progress has been made, but many others are likely to come in the near future, producing more and more ad hoc personalised therapies.
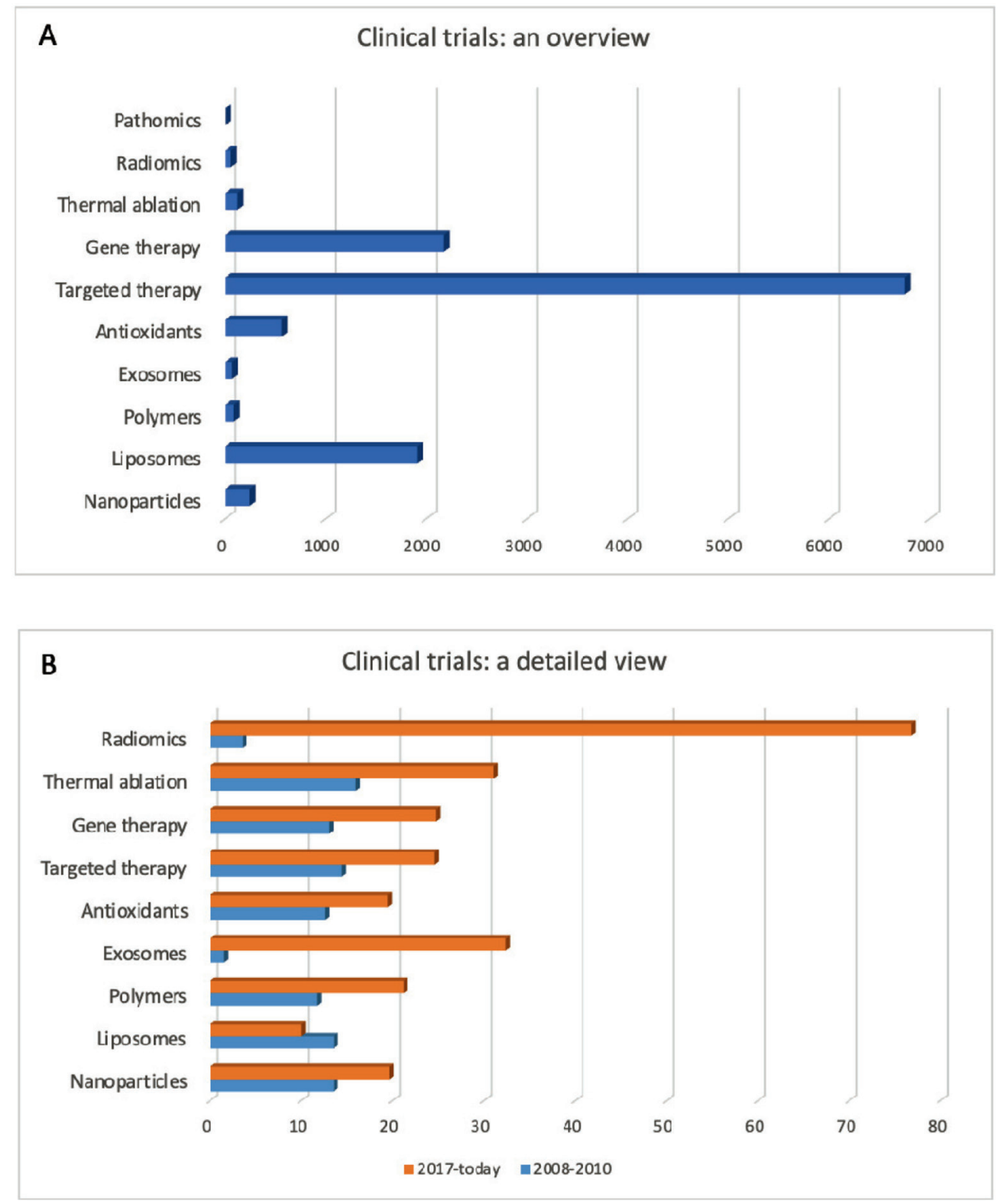

Figure 2. Cancer clinical trials. (A): Total number of clinical trials currently registered on www.clinicaltrials.gov for each approach discussed in this review. (B): Number of the clinical trials [in \% respect with the total studies shown in (A)] started during the years 2008-2010 (blue) and from 2017 until today (orange). Date accessed: 01/08/19 
Table 1. Advantages and disadvantages of the main innovative cancer therapeutic approaches.

\begin{tabular}{|c|c|c|}
\hline Strategy & Advantages & Disadvantages \\
\hline Nanoparticles & $\begin{array}{l}\text { - High stability and specificity } \\
\text { - Good biocompatibility and bioavailability }\end{array}$ & - It depends on the particular nanoparticle \\
\hline EVs & $\begin{array}{l}\text { - Physiologically secreted } \\
\text { - Good molecular characterisation } \\
\text { - High biocompatibility } \\
\text { - In vitro modifiable/loadable }\end{array}$ & $\begin{array}{l}\text { - Lack of preclinical procedures for isolation, quantification, } \\
\text { storage and drug loading }\end{array}$ \\
\hline Natural antioxidants & $\begin{array}{l}\text { - Easily available in large quantities } \\
\text { - Exploitation of their intrinsic properties }\end{array}$ & $\begin{array}{l}\text { - Limited bioavailability } \\
\text { - Possible toxicity }\end{array}$ \\
\hline Targeted therapy & $\begin{array}{l}\text { - High specificity } \\
\text { - Reduction of adverse reactions }\end{array}$ & - Lack of information regarding long-term side effects \\
\hline Gene therapy & $\begin{array}{l}\text { - Expression of pro-apoptotic and chemo-sensitising genes } \\
\text { - Expression of wild type tumour suppressor genes } \\
\text { - Expression of genes able to solicit specific anti-tumour } \\
\text { immune responses } \\
\text { - Targeted silencing of oncogenes and safety (RNAi) }\end{array}$ & $\begin{array}{l}\text { - Genome integration } \\
\text { - Limited efficacy in specific subsets of patients } \\
\text { - High chances to be neutralised by immune system } \\
\text { - Off-target effects and inflammation (RNAi) } \\
\text { - Need of ad hoc delivery systems (RNAi) } \\
\text { - Set-up of doses and suitable conditions for controlled release } \\
\text { (RNAi) }\end{array}$ \\
\hline $\begin{array}{l}\text { Thermal ablation } \\
\text { Magnetic hyperthermia }\end{array}$ & $\begin{array}{l}\text { - Precise treatment of the interested area } \\
\text { - Possibility to perform the treatment along with MRI imaging } \\
\text { (magnetic hyperthermia) }\end{array}$ & $\begin{array}{l}\text { - High efficiency only for localised areas } \\
\text { - Low penetration power } \\
\text { - Need for a skilled operator to perform the treatment }\end{array}$ \\
\hline Radiomics/pathomics & $\begin{array}{l}\text { - Creation of tumour whole tridimensional volume by non- } \\
\text { invasive imaging techniques } \\
\text { - Therapeutic and prognostic indicators of disease outcome }\end{array}$ & $\begin{array}{l}\text { - Definition of univocal data acquisition guidelines } \\
\text { - Standardisation of procedures to facilitate clinical translation } \\
\text { - Description of parameters and computational/statistical } \\
\text { methods to set robust protocols for the generation of models } \\
\text { for therapy }\end{array}$ \\
\hline
\end{tabular}

\section{Conflicts of interest}

The authors declare that they have no conflict of interest.

\section{Funding declaration}

This work was partially supported by the Fondazione CaRiPLo, grant no. 2018-0156 (Nanotechnological countermeasures against Oxidative stress in muscle cells Exposed to Microgravity-NOEMI) and by the European Research Council (ERC) under the European Union's Horizon 2020 Research and Innovation Programme (grant agreement N709613, SLaMM).

\section{Authors' contributions}

Carlotta Pucci and Chiara Martinelli contributed equally to this work. 


\section{References}

1. Dagogo-Jack I and Shaw AT (2018) Tumour heterogeneity and resistance to cancer therapies Nat Rev Clin Oncol 15(2) 81-94 https://doi. org/10.1038/nrclinonc.2017.166

2. Martinelli C, Pucci C, and Ciofani G (2019) Nanostructured carriers as innovative tools for cancer diagnosis and therapy APL Bioeng 3(1) 011502 https://doi.org/10.1063/1.5079943 PMID: 31069332 PMCID: 6481740

3. Kumar B, Garcia M, and Murakami JL, et al (2016) Exosome-mediated microenvironment dysregulation in leukemia Biochim Biophys Acta 1863(3) 464-470 https://doi.org/10.1016/j.bbamcr.2015.09.017

4. Chikara S, Nagaprashantha LD, and Singhal J, et al (2018) Oxidative stress and dietary phytochemicals: role in cancer chemoprevention and treatment Cancer Lett 413 122-134 https://doi.org/10.1016/j.canlet.2017.11.002

5. Singh S, Sharma B, and Kanwar SS, et al (2016) Lead phytochemicals for anticancer drug development Front Plant Sci 71667 https://doi. org/10.3389/fpls.2016.01667 PMID: 27877185 PMCID: 5099879

6. Bazak R, Houri M, and El Achy S, et al (2015) Cancer active targeting by nanoparticles: a comprehensive review of literature $J$ Cancer Res Clin Oncol 141(5) 769-784 https://doi.org/10.1007/s00432-014-1767-3

7. Lebedeva IV, Su ZZ, and Sarkar D, et al (2003) Restoring apoptosis as a strategy for cancer gene therapy: focus on p53 and mda-7 Semin Cancer Biol 13(2) 169-178 https://doi.org/10.1016/S1044-579X(02)00134-7 PMID: 12654260

8. Shanker M, Jin J, and Branch CD, et al (2011) Tumor suppressor gene-based nanotherapy: from test tube to the clinic J Drug Deliv 465845 https://doi.org/10.1155/2011/465845 PMID: 21490751 PMCID: 3065904

9. Vaishnaw AK, Gollob J, and Gamba-Vitalo C, et al (2010) A status report on RNAi therapeutics Silence 1(1) 14 https://doi.org/10.1186/ 1758-907X-1-14 PMID: 20615220 PMCID: 2908561

10. Brace C (2011) Thermal tumor ablation in clinical use IEEE Pulse 2(5) 28-38 https://doi.org/10.1109/MPUL.2011.942603 PMID: 25372967 PMCID: $\underline{4226271}$

11. Hervault A and Thanh NTK (2014) Magnetic nanoparticle-based therapeutic agents for thermo-chemotherapy treatment of cancer Nanoscale 6(20) 11553-11573 https://doi.org/10.1039/C4NR03482A PMID: 25212238

12. Yu KH, Zhang C, and Berry GJ, et al (2016) Predicting non-small cell lung cancer prognosis by fully automated microscopic pathology image features Nat Commun 712474 https://doi.org/10.1038/ncomms12474 PMID: 27527408 PMCID: 4990706

13. Aerts HJWL (2016) The potential of radiomic-based phenotyping in precision medicine a review JAMA Oncol 2(12) 1636-1642 https:// doi.org/10.1001/jamaoncol.2016.2631 PMID: 27541161

14. Grove O, Berglund AE, and Schabath MB, et al (2015) Quantitative computed tomographic descriptors associate tumor shape complexity and intratumor heterogeneity with prognosis in lung adenocarcinoma PLoS One 10(3) e0118261 https://doi.org/10.1371/journal. pone.0118261 PMID: 25739030 PMCID: 4349806

15. Aerts HJWL, Velazquez ER, and Leijenaar RTH, et al (2014) Decoding tumour phenotype by noninvasive imaging using a quantitative radiomics approach Nat Commun 54006 https://doi.org/10.1038/ncomms5006 PMID: 24892406 PMCID: 4059926

16. Kong J, Cooper LAD, and Wang F, et al (2013) Machine-based morphologic analysis of glioblastoma using whole-slide pathology images uncovers clinically relevant molecular correlates PLoS One 8(11) e81049 https://doi.org/10.1371/journal.pone.0081049 PMID: 24236209 PMCID: 3827469

17. Tinkle S, Mcneil SE, and Mühlebach S, et al (2014) Nanomedicines: addressing the scientific and regulatory gap Ann N Y Acad Sci 1313 35-56 https://doi.org/10.1111/nyas.12403 PMID: 24673240 
18. Albanese A, Tang PS, and Chan WCW (2012) The effect of nanoparticle size, shape, and surface chemistry on biological systems Annu Rev Biomed Eng 14 1-16 https://doi.org/10.1146/annurev-bioeng-071811-150124 PMID: 22524388

19. Maeda $\mathrm{H}$ (2015) Toward a full understanding of the EPR effect in primary and metastatic tumors as well as issues related to its heterogeneity Adv Drug Deliv Rev 91 3-6 https://doi.org/10.1016/j.addr.2015.01.002 PMID: 25579058

20. Gerlowski LE and Jain RK (1986) Microvascular permeability of normal and neoplastic tissues Microvasc Res 31(3) 288-305 https://doi. org/10.1016/0026-2862(86)90018-X PMID: 2423854

21. Shi J, Kantoff PW, and Wooster R, et al (2017) Cancer nanomedicine: progress, challenges and opportunities Nat Rev Cancer 17(1) 20-37 https://doi.org/10.1038/nrc.2016.108 PMCID: 5575742

22. Shi J, Votruba AR, and Farokhzad OC, et al (2010) Nanotechnology in drug delivery and tissue engineering: from discovery to applications Nano Lett 10(9) 3223-3230 https://doi.org/10.1021/nl102184c PMID: 20726522 PMCID: 2935937

23. Sinha R (2006) Nanotechnology in cancer therapeutics: bioconjugated nanoparticles for drug delivery Mol Cancer Ther 5(8) 1909-1917 https://doi.org/10.1158/1535-7163.MCT-06-0141 PMID: 16928810

24. Bregoli L, Movia D, and Gavigan-Imedio JD, et al (2016) Nanomedicine applied to translational oncology: a future perspective on cancer treatment Nanomed 12(1) 81-103 https://doi.org/10.1016/j.nano.2015.08.006

25. Kim EM and Jeong HJ (2017) Current status and future direction of nanomedicine: focus on advanced biological and medical applications Nucl Med Mol Imaging 51(2) 106-117 https://doi.org/10.1007/s13139-016-0435-8 PMID: 28559935 PMCID: 5429296

26. May JP and Li S-D (2013) Hyperthermia-induced drug targeting Expert Opin Drug Deliv 10(4) 511-527 https://doi.org/10.1517/17425 247.2013.758631 PMID: 23289519

27. Matea CT, Mocan T, and Tabaran F, et al (2017) Quantum dots in imaging, drug delivery and sensor applications Int J Nanomed 12 5421-5431 https://doi.org/10.2147/IJN.S138624

28. Gao J, Chen K, and Miao Z, et al (2011) Affibody-based nanoprobes for HER2-expressing cell and tumor imaging Biomaterials 32(8) 2141-2148 https://doi.org/10.1016/j.biomaterials.2010.11.053 PMCID: 3032351

29. Leiner T, Gerretsen S, and Botnar R, et al (2005) Magnetic resonance imaging of atherosclerosis. European Radiology 15(6) 1087-1099 https://doi.org/10.1007/s00330-005-2646-8

30. Boyer C, Whittaker MR, and Bulmus V, et al (2010) The design and utility of polymer-stabilized iron-oxide nanoparticles for nanomedicine applications NPG Asia Materials 2 23-30 https://doi.org/10.1038/asiamat.2010.6

31. Sanchez C, Belleville P, and Popall M, et al (2011) Applications of advanced hybrid organic-inorganic nanomaterials: from laboratory to market Chem Soc Rev 40(2) 696-753 https://doi.org/10.1039/c0cs00136h PMID: 21229132

32. Sun T, Zhang YS, and Pang B, et al (2014) Engineered nanoparticles for drug delivery in cancer therapy Angew Chem Int Ed Engl 53(46) 12320-12464 PMID: 25294565

33. Connor EE, Mwamuka J, and Gole A, et al (2005) Gold nanoparticles are taken up by human cells but do not cause acute cytotoxicity Small 1(3) 325-327 https://doi.org/10.1002/smll.200400093

34. Abadeer NS and Murphy CJ (2016) Recent progress in cancer thermal therapy using gold nanoparticles J Phys Chem C 120(9) 4691-4716 https://doi.org/10.1021/acs.jpcc.5b11232

35. Zhong J, Wen L, and Yang S, et al (2015) Imaging-guided high-efficient photoacoustic tumor therapy with targeting gold nanorods Nanomed 11(6) 1499-1509 https://doi.org/10.1016/j.nano.2015.04.002

36. Stuchinskaya T, Moreno M, and Cook MJ, et al (2011) Targeted photodynamic therapy of breast cancer cells using antibody-phthalocyaninegold nanoparticle conjugates Photochem Photobiol Sci 10(5) 822-831 https://doi.org/10.1039/c1pp05014a PMID: 21455532 
37. Gubernator J (2011) Active methods of drug loading into liposomes: recent strategies for stable drug entrapment and increased in vivo activity Expert Opin Drug Deliv 8(5) 565-580 https://doi.org/10.1517/17425247.2011.566552 PMID: 21492058

38. Narang AS, Delmarre D, and Gao D (2007) Stable drug encapsulation in micelles and microemulsions Int J Pharm 345(1-2) 9-25 https:// doi.org/10.1016/j.ijpharm.2007.08.057 PMID: 17945446

39. Barenholz Y (2012) Doxil-the first FDA-approved nano-drug: lessons learned J Control Release 160(2) 117-134 https://doi. org/10.1016/j.jconrel.2012.03.020 PMID: 22484195

40. Markman M (2006) Pegylated liposomal doxorubicin in the treatment of cancers of the breast and ovary Expert Opin Pharmacother 7(11) 1469-1474 https://doi.org/10.1517/14656566.7.11.1469 PMID: 16859430

41. Hofheinz RD, Gnad-Vogt SU, and Beyer U, et al (2005) Liposomal encapsulated anti-cancer drugs Anticancer Drugs 16(7) 691-707 https://doi.org/10.1097/01.cad.0000167902.53039.5a PMID: 16027517

42. Malam Y, Loizidou M, and Seifalian AM (2009) Liposomes and nanoparticles: nanosized vehicles for drug delivery in cancer Trends Pharmacol Sci 30(11) 592-599 https://doi.org/10.1016/j.tips.2009.08.004 PMID: 19837467

43. Nasir A, Kausar A, and Younus A (2015) A review on preparation, properties and applications of polymeric nanoparticle-based materials Polym-Plast Technol Eng 54(4) 325-341 https://doi.org/10.1080/03602559.2014.958780

44. Waghmare AS, Grampurohit ND, and Gadhave MV, et al (2012) Solid lipid nanoparticles: a promising drug delivery system Int Res J Pharmacy 3(4) 100-107

45. Liu J, Xiao Y, and Allen C (2004) Polymer-drug compatibility: a guide to the development of delivery systems for the anticancer agent, ellipticine J Pharm Sci 93(1) 132-143 https://doi.org/10.1002/jps.10533

46. Ganesan P and Narayanasamy D (2017) Lipid nanoparticles: different preparation techniques, characterization, hurdles, and strategies for the production of solid lipid nanoparticles and nanostructured lipid carriers for oral drug delivery Sustainable Chemistry and Pharmacy 6 37-56 https://doi.org/10.1016/j.scp.2017.07.002

47. Müller RH, Radtke M, and Wissing SA (2002) Nanostructured lipid matrices for improved microencapsulation of drugs Int J Pharm 242(1-2) 121-128 https://doi.org/10.1016/S0378-5173(02)00180-1 PMID: 12176234

48. Kreuter J, Ramge P, and Petrov V, et al (2003) Direct evidence that polysorbate-80-coated poly(butylcyanoacrylate) nanoparticles deliver drugs to the CNS via specific mechanisms requiring prior binding of drug to the nanoparticles Pharm Res 20(3) 409-416 https:// doi.org/10.1023/A:1022604120952 PMID: 12669961

49. Grillone A, Riva ER, and Mondini A, et al (2015) Active targeting of sorafenib: preparation, characterization, and in vitro testing of drug-loaded magnetic solid lipid nanoparticles Adv Healthc Mater 4(11) 1681-1690 https://doi.org/10.1002/adhm.201500235 PMID: 26039933

50. Tapeinos C, Marino A, and Battaglini M, et al (2018) Stimuli-responsive lipid-based magnetic nanovectors increase apoptosis in glioblastoma cells through synergic intracellular hyperthermia and chemotherapy Nanoscale 11(1) 72-88 https://doi.org/10.1039/ C8NR05520C PMID: 30357214 PMCID: 6336008

51. Gillies ER and Fréchet JMJ (2005) Dendrimers and dendritic polymers in drug delivery Drug Discov Today 10(1) 35-43 https://doi. org/10.1016/S1359-6446(04)03276-3 PMID: 15676297

52. Kesharwani P, Jain K, and Jain NK (2014) Dendrimer as nanocarrier for drug delivery Prog Polym Sci 39(2) 268-307 https://doi.org/ 10.1016/j.progpolymsci.2013.07.005

53. Al-jamal KT, Rubio N, and Buddle J, et al (2013) Cationic poly-l-lysine dendrimer complexes doxorubicin and delays tumor growth in vitro and in vivo ACS Nano 7(3) 1905-1917 https://doi.org/10.1021/nn305860k PMID: 23527750 
54. ClinicalTrials.gov. US National Library of Medicine [https://clinicaltrials.gov/ct2/show/NCT03255343] Date accessed: 01/08/19

55. Colombo M, Raposo G, and Théry C (2014) Biogenesis, secretion, and intercellular interactions of exosomes and other extracellular vesicles Annu Rev Cell Dev Biol 30 255-289 https://doi.org/10.1146/annurev-cellbio-101512-122326 PMID: 25288114

56. Vlassov AV, Magdaleno S, and Setterquist R, et al (2012) Exosomes: current knowledge of their composition, biological functions, and diagnostic and therapeutic potentials Biochim Biophys Acta 1820(7) 940-948 https://doi.org/10.1016/j.bbagen.2012.03.017 PMID: 22503788

57. Thery C (2011) Exosomes: secreted vesicles and intercellular communications F1000 Biol Rep 315 https://doi.org/10.3410/B3-15 PMID: 21876726 PMCID: 3155154

58. Witwer KW, Buzas El, and Bemis LT, et al (2013) Standardization of sample collection, isolation and analysis methods in extracellular vesicle research: an ISEV position paper J Extracell Vesicles 2 https://doi.org/10.3402/jev.v2i0.20360

59. Luga V and Wrana JL (2013) Tumor-stroma interaction: revealing fibroblast-secreted exosomes as potent regulators of Wnt-planar cell polarity signaling in cancer metastasis Cancer Res 73(23) 6843-6847 https://doi.org/10.1158/0008-5472.CAN-13-1791 PMID: 24265274

60. Suetsugu A, Honma K, and Saji S, et al (2013) Imaging exosome transfer from breast cancer cells to stroma at metastatic sites in orthotopic nude-mouse models Adv Drug Deliv Rev 65(3) 383-390 https://doi.org/10.1016/j.addr.2012.08.007

61. Raimondo S, Saieva L, and Corrado C, et al (2015) Chronic myeloid leukemia-derived exosomes promote tumor growth through an autocrine mechanism Cell Commun Signal 138 https://doi.org/10.1186/s12964-015-0086-x PMID: 25644060 PMCID: 4320527

62. Martinelli C (2017) Exosomes: new biomarkers for targeted cancer therapy Molecular Oncology: Underlying Mechanisms and Translational Advancements 1st edn, ed (Springer) (Switzerland AG: Springer Nature) chapter 6 pp 129-157

63. Siravegna G, Marsoni S, and Siena S, et al (2017) Integrating liquid biopsies into the management of cancer Nat Rev Clin Oncol 14(9) 531-548 https://doi.org/10.1038/nrclinonc.2017.14 PMID: 28252003

64. Kosaka N, Urabe F, and Egawa S, et al (2017) The small vesicular culprits: the investigation of extracellular vesicles as new targets for cancer treatment Clin Transl Med 6(1) 45 https://doi.org/10.1186/s40169-017-0176-z PMID: 29238879 PMCID: 5729179

65. Thakur BK, Zhang H, and Becker A, et al (2014) Double-stranded DNA in exosomes: a novel biomarker in cancer detection Cell Res 24(6) 766-769 https://doi.org/10.1038/cr.2014.44 PMID: 24710597 PMCID: 4042169

66. Kahlert C, Melo SA, and Protopopov A, et al (2014) Identification of double stranded genomic dna spanning all chromosomes with mutated KRAS and P53 DNA in the serum exosomes of patients with pancreatic cancer J Biol Chem 289(7) 3869-3875 https://doi. org/10.1074/jbc.C113.532267 PMID: 24398677 PMCID: 3924256

67. Valadi $\mathrm{H}$, Ekström $\mathrm{K}$, and Bossios A, et al (2007) Exosome-mediated transfer of mRNAs and microRNAs is a novel mechanism of genetic exchange between cells Nat Cell Biol 9(6) 654-659 https://doi.org/10.1038/ncb1596 PMID: 17486113

68. Simpson RJ, Lim JWE, and Moritz RL, et al (2009) Exosomes: proteomic insights and diagnostic potential Expert Rev Proteomics 6(3) 267-283 https://doi.org/10.1586/epr.09.17 PMID: 19489699

69. Yang S, Che SPY, and Kurywchak P, et al (2017) Detection of mutant KRAS and TP53 DNA in circulating exosomes from healthy individuals and patients with pancreatic cancer Cancer Biol Ther 18(3) 158-165 https://doi.org/10.1080/15384047.2017.1281499 PMID: 28121262 PMCID: 5389423

70. Allenson K, Castillo J, and San Lucas FA, et al (2017) High prevalence of mutant KRAS in circulating exosome-derived DNA from earlystage pancreatic cancer patients Ann Oncol 28(4) 741-747 PMID: 28104621 PMCID: 5834026

71. Del Re M, Biasco E, and Crucitta S, et al (2017) The detection of androgen receptor splice variant 7 in plasma-derived exosomal rna strongly predicts resistance to hormonal therapy in metastatic prostate cancer patients Eur Urol 71(4) 680-687 https://doi. org/10.1016/j.eururo.2016.08.012 
72. McKiernan J, Donovan MJ, and O'Neill V, et al (2016) A novel urine exosome gene expression assay to predict high-grade prostate cancer at initial biopsy JAMA Oncol 2(7) 882-889 https://doi.org/10.1001/jamaoncol.2016.0097 PMID: 27032035

73. Liu T, Zhang X, and Gao S, et al (2016) Exosomal long noncoding RNA CRNDE-h as a novel serum-based biomarker for diagnosis and prognosis of colorectal cancer Oncotarget 7(51) 85551-85563 https://doi.org/10.18632/oncotarget.13465 PMID: 27888803 PMCID: 5356757

74. Cazzoli R, Buttitta F, and Di Nicola M, et al (2013) MicroRNAs derived from circulating exosomes as noninvasive biomarkers for screening and diagnosing lung cancer J Thorac Oncol 8(9) 1156-1162 https://doi.org/10.1097/JTO.0b013e318299ac32 PMID: 23945385 PMCID: 4123222

75. Melo SA, Luecke LB, and Kahlert C, et al (2015) Glypican-1 identifies cancer exosomes and detects early pancreatic cancer Nature 523(7559) 177-182 https://doi.org/10.1038/nature14581 PMID: 26106858 PMCID: 4825698

76. Costa-Silva B, Aiello NM, and Ocean AJ, et al (2015) Pancreatic cancer exosomes initiate pre-metastatic niche formation in the liver Nat Cell Biol 17(6) 816-826 https://doi.org/10.1038/ncb3169 PMID: 25985394 PMCID: 5769922

77. Skotland T, Ekroos K, and Kauhanen D, et al (2017) Molecular lipid species in urinary exosomes as potential prostate cancer biomarkers Eur J Cancer 70 122-132 https://doi.org/10.1016/j.ejca.2016.10.011

78. Sun D, Zhuang X, and Xiang X, et al (2010) A novel nanoparticle drug delivery system: the anti-inflammatory activity of curcumin is enhanced when encapsulated in exosomes Mol Ther 18(9) 1606-1614 https://doi.org/10.1038/mt.2010.105 PMID: 20571541 PMCID: 2956928

79. Kim MS, Haney MJ, and Zhao Y, et al (2016) Development of exosome-encapsulated paclitaxel to overcome MDR in cancer cells Nanomed 12(3) 655-664 https://doi.org/10.1016/j.nano.2015.10.012

80. Qi H, Liu C, and Long L, et al (2016) Blood exosomes endowed with magnetic and targeting properties for cancer therapy ACS Nano 10(3) 3323-3333 https://doi.org/10.1021/acsnano.5b06939 PMID: 26938862

81. Jang SC, Kim OY, and Yoon CM, et al (2013) Bioinspired exosome-mimetic nanovesicles for targeted delivery of chemotherapeutics to malignant tumors ACS Nano 7(9) 7698-7710 https://doi.org/10.1021/nn402232g PMID: 24004438

82. Yang T, Martin P, and Fogarty B, et al (2015) Exosome delivered anticancer drugs across the blood-brain barrier for brain cancer therapy in Danio Rerio Pharm Res 32(6) 2003-2014 https://doi.org/10.1007/s11095-014-1593-y PMID: 25609010 PMCID: 4520542

83. Kim MS, Haney MJ, and Zhao Y, et al (2018) Engineering macrophage-derived exosomes for targeted paclitaxel delivery to pulmonary metastases: in vitro and in vivo evaluations Nanomed 14(1) 195-204 https://doi.org/10.1016/j.nano.2017.09.011

84. Hadla M, Palazzolo S, and Corona G, et al (2016) Exosomes increase the therapeutic index of doxorubicin in breast and ovarian cancer mouse models Nanomed (Lond) 11(18) 2431-2441 https://doi.org/10.2217/nnm-2016-0154

85. ClinicalTrials.gov. US National Library of Medicine [https://clinicaltrials.gov/ct2/show/NCT01294072] Date accessed: 15/05/19

86. ClinicalTrials.gov. US National Library of Medicine [https://clinicaltrials.gov/ct2/show/NCT02657460] Date accessed: 15/05/19

87. ClinicalTrials.gov. US National Library of Medicine [https://clinicaltrials.gov/ct2/show/NCT03230708] Date accessed: 15/05/19

88. Mizrak A, Bolukbasi MF, and Ozdener GB, et al (2013) Genetically engineered microvesicles carrying suicide mRNA/protein inhibit schwannoma tumor growth Mol Ther 21(1) 101-108 https://doi.org/10.1038/mt.2012.161 PMCID: 3538300

89. Ohno SI, Takanashi M, and Sudo K, et al (2013) Systemically injected exosomes targeted to EGFR deliver antitumor microrna to breast cancer cells Mol Ther 21(1) 185-191 https://doi.org/10.1038/mt.2012.180 PMCID: 3538304

90. Cho JA, Yeo DJ, and Son HY, et al (2005) Exosomes: a new delivery system for tumor antigens in cancer immunotherapy Int J Cancer 114(4) 613-622 https://doi.org/10.1002/ijc.20757 
91. Lapierre V, Théry C, and Virault-Rocroy $\mathrm{P}$, et al (2010) Updated technology to produce highly immunogenic dendritic cell-derived exosomes of clinical grade J Immunother 34(1) 65-75 https://doi.org/10.1097/CJl.0b013e3181fe535b

92. Besse B, Charrier M, and Lapierre V, et al (2016) Dendritic cell-derived exosomes as maintenance immunotherapy after first line chemotherapy in NSCLC Oncoimmunology 5(4) e1071008 https://doi.org/10.1080/2162402X.2015.1071008 PMID: 27141373 PMCID: 4839329

93. Dai S, Wei D, and Wu Z, et al (2008) Phase I clinical trial of autologous ascites-derived exosomes combined with GM-CSF for colorectal cancer Mol Ther 16(4) 782-790 https://doi.org/10.1038/mt.2008.1 PMID: 18362931

94. Boriachek K, Islam MN, and Möller A, et al (2018) Biological functions and current advances in isolation and detection strategies for exosome nanovesicles Small 14(6) 1702153 (1-21) https://doi.org/10.1002/smll.201702153

95. Cadet J, Douki T, and Ravanat JL (1997) Artifacts associated with the measurement of oxidized DNA bases Environ Health Perspect 105(10) 1034-1039 PMID: 9349826 PMCID: 1470384

96. Floyd RA, Watson JJ, and Wong PK, et al (1986) Hydroxyl free radical adduct of deoxyguanosine: sensitive detection and mechanisms of formation Free Radic Res Commun 1(3) 163-172 https://doi.org/10.3109/10715768609083148 PMID: 2577733

97. Gupta RK, Patel AK, and Shah N, et al (2014) Oxidative stress and cancer: an overview Asian Pac J Cancer Prev 15(11) 4405-4409 https://doi.org/10.7314/APJCP.2014.15.11.4405 PMID: 24969860

98. Gille G and Sigler K (1995) Oxidative stress and living cells Folia Microbiol (Praha) 40(2) 131-152 https://doi.org/10.1007/BF02815413

99. Halliwell B (2006) Oxidative stress and cancer: have we moved forward? Biochem J 401(1) 1-11 https://doi.org/10.1042/BJ20061131 PMID: 17150040

100.Katz L and Baltz RH (2016) Natural product discovery: past, present, and future J Ind Microbiol Biotechnol 43(2-3) 155-176 https://doi. org/10.1007/s10295-015-1723-5 PMID: 26739136

101.Bernardini S, Tiezzi A, and Laghezza Masci V, et al (2018) Natural products for human health: an historical overview of the drug discovery approaches Nat Prod Res 32(16) 1926-1950 https://doi.org/10.1080/14786419.2017.1356838

102.Iqbal J, Abbasi BA, and Mahmood T, et al (2017) Plant-derived anticancer agents: a green anticancer approach Asian Pac J Trop Biomed 7(12) 1129-1150 https://doi.org/10.1016/j.apjtb.2017.10.016

103.González-Vallinas M, González-Castejón M, and Rodríguez-Casado A, et al (2013) Dietary phytochemicals in cancer prevention and therapy: a complementary approach with promising perspectives Nutr Rev 71(9) 585-599 https://doi.org/10.1111/nure.12051 PMID: 24032363

104. Kocaadam B and Şanlier N (2017) Curcumin, an active component of turmeric (Curcuma longa), and its effects on health Crit Rev Food Sci Nutr 57(13) 2889-2895 https://doi.org/10.1080/10408398.2015.1077195

105.Imran M, Ullah A, and Saeed F, et al (2018) Cucurmin, anticancer, \& antitumor perspectives: a comprehensive review Crit Rev Food Sci Nutr 58(8) 1271-1293 https://doi.org/10.1080/10408398.2016.1252711

106.Perrone D, Ardito F, and Giannatempo G, et al (2015) Biological and therapeutic activities, and anticancer properties of curcumin Exp Ther Med 10(5) 1615-1623 https://doi.org/10.3892/etm.2015.2749 PMID: 26640527 PMCID: 4665301

107.Sordillo PP and Helson L (2015) Curcumin and cancer stem cells: curcumin has asymmetrical effects on cancer and normal stem cells Anticancer Res 35(2) 599-614 PMID: 25667437

108. Kumar G, Mittal S, and Sak K, et al (2016) Molecular mechanisms underlying chemopreventive potential of curcumin: current challenges and future perspectives Life Sci 148 312-328 https://doi.org/10.1016/j.Ifs.2016.02.022 
109.Kunnumakkara AB, Bordoloi D, and Harsha C, et al (2017) Curcumin mediates anticancer effects by modulating multiple cell signaling pathways Clin Sci (Lond) 131(15) 1781-1799 https://doi.org/10.1042/CS20160935

110.Wang YJ, Pan MH, and Cheng AL, et al (1997) Stability of curcumin in buffer solutions and characterization of its degradation products J Pharm Biomed Anal 15(12) 1867-1876 https://doi.org/10.1016/S0731-7085(96)02024-9 PMID: 9278892

111.Rahimi HR, Nedaeinia R, and Sepehri Shamloo A, et al (2016) Novel delivery system for natural products: nano-curcumin formulations Avicenna J Phytomed 6(4) 383-398 PMID: 27516979 PMCID: 4967834

112.Liu W, Zhai Y, and Heng X, et al (2016) Oral bioavailability of curcumin: problems and advancements J Drug Target 24(8) 694-702 https://doi.org/10.3109/1061186X.2016.1157883 PMID: 26942997

113.ClinicalTrials.gov. US National Library of Medicine [https://clinicaltrials.gov/ct2/results?term=curcumin+cancer\&Search=Apply\&recrs= $b \& r e c r s=a \& r e c r s=f \& r e c r s=d \& r e c r s=e \& a g e \_v=\& g n d r=\&$ type=\&rslt=] Date accessed: $15 / 05 / 19$

114.Farooqi AA, Qureshi MZ, and Khalid S, et al (2019) Regulation of cell signaling pathways by berberine in different cancers: searching for missing pieces of an incomplete jig-saw puzzle for an effective cancer therapy Cancers (Basel) 11(4) pii: E478 https://doi.org/10.3390/ cancers11040478

115.Mohammadinejad R, Ahmadi Z, and Tavakol S, et al (2019) Berberine as a potential autophagy modulator J Cell Physiol https://doi. org/10.1002/jcp.28325

116.Bianchi S and Giovannini L (2018) Inhibition of mTOR/S6K1/4E-BP1 signaling by nutraceutical sirt1 modulators Nutr Cancer 70(3) 490-501 https://doi.org/10.1080/01635581.2018.1446093 PMID: 29537893

117.Wang ZP, Wu JB, and Chen T-S, et al (2015) In vitro and in vivo antitumor efficacy of berberine-nanostructured lipid carriers against H22 tumor Progress in Biomedical Optics and Imaging-Proceedings of SPIE 9324 id 93240Y 8 pp https://doi.org/10.1117/12.2079107

118. Kabary DM, Helmy MW, and Abdelfattah E-ZA, et al (2018) Inhalable multi-compartmental phospholipid enveloped lipid core nanocomposites for localized mTOR inhibitor/herbal combined therapy of lung carcinoma Eur J Pharm Biopharm 130 152-164 https://doi. org/10.1016/j.ejpb.2018.06.027 PMID: 29964122

119.Shen R, Kim JJ, and Yao M, et al (2016) Development and evaluation of vitamin E D-a-tocopheryl polyethylene glycol 1000 succinatemixed polymeric phospholipid micelles of berberine as an anticancer nanopharmaceutical Int J Nanomedicine 11 1687-1700 PMCID: 4853014

120.ClinicalTrials.gov. US National Library of Medicine [https://clinicaltrials.gov/ct2/results?term=berberine+cancer\&Search=Apply\&recrs= $\left.b \& r e c r s=a \& r e c r s=f \& r e c r s=d \& r e c r s=e \& a g e \_v=\& g n d r=\& t y p e=\& r s \mid t=\right]$ Date accessed: $15 / 05 / 19$

121.Liu Y, Tang ZG, and Lin Y, et al (2017) Effects of quercetin on proliferation and migration of human glioblastoma U251 cells Biomed Pharmacother 92 33-38 https://doi.org/10.1016/j.biopha.2017.05.044 PMID: 28528183

122. Murakami A, Ashida H, and Terao J (2008) Multitargeted cancer prevention by quercetin Cancer Lett 269(2) 315-325 https://doi. org/10.1016/j.canlet.2008.03.046 PMID: $\underline{18467024}$

123. Yang F, Song L, and Wang H, et al (2015) Quercetin in prostate cancer: Chemotherapeutic and chemopreventive effects, mechanisms and clinical application potential (review) Oncol Rep 33(6) 2659-2668 https://doi.org/10.3892/or.2015.3886 PMID: 25845380

124.Shih H, Pickwell GV, and Quattrochi LC (2000) Differential effects of flavonoid compounds on tumor promoter-induced activation of the human CYP1A2 enhancer Arch Biochem Biophys 373(1) 287-294 https://doi.org/10.1006/abbi.1999.1550 PMID: 10620351

125.Brito AF, Ribeiro M, and Abrantes AM, et al (2015) Quercetin in cancer treatment, alone or in combination with conventional therapeutics? Curr Med Chem 22(26) 305-339 https://doi.org/10.2174/0929867322666150812145435 
126.ClinicalTrials.gov. US National Library of Medicine [https://clinicaltrials.gov/ct2/results?term=quercetin+cancer\&Search=Apply\&recrs= $\left.b \& r e c r s=a \& r e c r s=f \& r e c r s=d \& r e c r s=e \& a g e \_v=\& g n d r=\& t y p e=\& r s \mid t=\right]$ Date accessed: 15/05/19

127.Alasvand N, Urbanska AM, and Rahmati M, et al (2017) Therapeutic nanoparticles for targeted delivery of anticancer drugs Multifunctional Systems for Combined Delivery, Biosensing and Diagnostics 1st edn, ed (Elsevier) chapter 13 pp 245-259 https://doi.org/10.1016/ B978-0-323-52725-5.00013-7

128.Barua S and Mitragotri S (2014) Challenges associated with penetration of nanoparticles across cell and tissue barriers: A review of current status and future prospects Nano Today 9(2) 223-243 https://doi.org/10.1016/j.nantod.2014.04.008 PMID: 25132862 PMCID: 4129396

129.Xu S, Olenyuk BZ, and Okamoto CT, et al (2013) Targeting receptor-mediated endocytotic pathways with nanoparticles: rationale and advances Adv Drug Deliv Rev 65(1) 121-138 https://doi.org/10.1016/j.addr.2012.09.041

130. Hymel D and Peterson BR (2012) Synthetic cell surface receptors for delivery of therapeutics and probes Adv Drug Deliv Rev 64(9) 797-810 https://doi.org/10.1016/j.addr.2012.02.007 PMID: 22401875 PMCID: 3359398

131.Senol S, Ceyran AB, and Aydin A, et al (2015) Folate receptor $a$ expression and significance in endometrioid endometrium carcinoma and endometrial hyperplasia Int J Clin Exp Pathol 8(5) 5633-5641 PMID: 26191275 PMCID: 4503146

132.Tao W, Zhang J, and Zeng X, et al (2015) Blended nanoparticle system based on miscible structurally similar polymers: a safe, simple, targeted, and surprisingly high efficiency vehicle for cancer therapy Adv Healthc Mater 4(8) 1203-1214 https://doi.org/10.1002/ adhm.201400751 PMID: 25800699

133.Byrne JD, Betancourt T, and Brannon-Peppas $L$ et al (2008) Active targeting schemes for nanoparticle systems in cancer therapeutics Advanced Drug Delivery Rev 60(15) 1615-1626 https://doi.org/10.1016/j.addr.2008.08.005

134.Yu B, Tai HC, and Xue W, et al (2010) Receptor-targeted nanocarriers for therapeutic delivery to cancer Mol Membr Biol 27(7) 286-298 https://doi.org/10.3109/09687688.2010.521200 PMID: 21028937 PMCID: 3789246

135.Demeule M, Currie JC, and Bertrand Y, et al (2008) Involvement of the low-density lipoprotein receptor-related protein in the transcytosis of the brain delivery vector Angiopep-2 J Neurochem 106(4) 1534-1544 https://doi.org/10.1111/j.1471-4159.2008.05492.x PMID: 18489712

136. Huang S, Li J, and Han L, et al (2011) Dual targeting effect of Angiopep-2-modified, DNA-loaded nanoparticles for glioma Biomaterials 32(28) 6832-6838 https://doi.org/10.1016/j.biomaterials.2011.05.064 PMID: 21700333

137.Kulhari H, Pooja D, and Shrivastava S, et al (2014) Peptide conjugated polymeric nanoparticles as a carrier for targeted delivery of docetaxel Colloids Surf B Biointerfaces 117 166-173 https://doi.org/10.1016/j.colsurfb.2014.02.026 PMID: 24632389

138.Cornelio DB, Roesler R, and Schwartsmann G (2007) Gastrin-releasing peptide receptor as a molecular target in experimental anticancer therapy Ann Oncol 18(9) 1457-1466 https://doi.org/10.1093/annonc/mdm058 PMID: 17351255

139.Recht L, Torres CO, and Smith TW, et al (1990) Transferrin receptor in normal and neoplastic brain tissue: implications for brain-tumor immunotherapy J Neurosurg 72(6) 941-945 https://doi.org/10.3171/jns.1990.72.6.0941 PMID: 2159987

140.Daniels TR, Bernabeu E, and Rodríguez JA, et al (2012) The transferrin receptor and the targeted delivery of therapeutic agents against cancer Biochim Biophys Acta 1820(3) 291-317 https://doi.org/10.1016/j.bbagen.2011.07.016 PMCID: 3500658

141. Muhamad N, Plengsuriyakarn T, and Na-Bangchang K (2018) Application of active targeting nanoparticle delivery system for chemotherapeutic drugs and traditional/herbal medicines in cancer therapy: a systematic review Int J Nanomedicine 13 3921-3935 https:// doi.org/10.2147/IJN.S165210 PMID: 30013345 PMCID: 6038858

142. Ni X, Castanares M, and Mukherjee A, et al (2011) Nucleic acid aptamers: clinical applications and promising new horizons Curr Med Chem 18(27) 4206-4214 https://doi.org/10.2174/092986711797189600 PMID: 21838685 PMCID: 3260938 
143.Farokhzad OC, Cheng J, and Teply BA, et al (2006) Targeted nanoparticle-aptamer bioconjugates for cancer chemotherapy in vivo Proc Natl Acad Sci USA 103(16) 6315-20 https://doi.org/10.1073/pnas.0601755103 PMID: 16606824 PMCID: 1458875

144.Bagalkot V, Zhang L, and Levy-Nissenbaum E, et al (2007) Quantum dot-aptamer conjugates for synchronous cancer imaging, therapy, and sensing of drug delivery based on Bi-fluorescence resonance energy transfer Nano Lett 7(10) 3065-3070 https://doi.org/10.1021/ nI071546n PMID: 17854227

145.Sharkey RM and Goldenberg DM (2009) Targeted therapy of cancer: new prospects for antibodies and immunoconjugates CA Cancer J Clin 56(4) 226-243 https://doi.org/10.3322/canjclin.56.4.226

146.Acharya S, Dilnawaz F, and Sahoo SK (2009) Targeted epidermal growth factor receptor nanoparticle bioconjugates for breast cancer therapy Biomaterials 30(29) 5737-5750 https://doi.org/10.1016/j.biomaterials.2009.07.008 PMID: 19631377

147.Ulbrich K, Hekmatara T, and Herbert E, et al (2009) Transferrin- and transferrin-receptor-antibody-modified nanoparticles enable drug delivery across the blood-brain barrier (BBB) Eur J Pharm Biopharm 71(2) 251-256 https://doi.org/10.1016/j.ejpb.2008.08.021

148.McCune JS (2018) Rapid advances in immunotherapy to treat cancer Clin Pharmacol Ther 103(4) 540-544 https://doi.org/10.1002/ cpt.985 PMID: 29527663

149.U.S. Food \& DrugAdministration [https://www.accessdata.fda.gov/scripts/cder/daf/index.cfm?event=overview.process\&varApplNo=103705] Date accessed: 15/05/19

150.U.S. Food \& Drug Administration [https://www.accessdata.fda.gov/drugsatfda_docs/nda/2002/125019_0000_ZevalinTOC.cfm] Date accessed: $15 / 05 / 19$

151.U.S. Food \& DrugAdministration [https://www.accessdata.fda.gov/scripts/cder/daf/index.cfm?event=overview.process\&varAppINo=125427] Date accessed: 15/05/19

152.U.S. Food and Drug Administration [https://www.accessdata.fda.gov/drugsatfda_docs/label/2017/125554s055lbl.pdf] Date accessed: 15/05/19

153.U.S. Food \& Drug Administration [https://www.accessdata.fda.gov/drugsatfda_docs/label/2018/125514s034lbl.pdf] Date accessed: $15 / 05 / 19$

154.Rosenberg SA, Restifo NP, and Yang JC, et al (2008) Adoptive cell transfer: a clinical path to effective cancer immunotherapy Nat Rev Cancer 8(4) 299-308 https://doi.org/10.1038/nrc2355 PMID: 18354418 PMCID: 2553205

155. Miliotou AN and Papadopoulou LC (2018) CAR t-cell therapy: a new era in cancer immunotherapy Curr Pharm Biotechnol 191 5-18 https://doi.org/10.2174/1389201019666180418095526

156.Friedmann T (1992) A brief history of gene therapy Nat Genet 2(2) 93-98 https://doi.org/10.1038/ng1092-93 PMID: 1303270

157.Rosenberg SA, Aebersold P, and Cornetta K, et al (1990) Gene transfer into humans-immunotherapy of patients with advanced melanoma, using tumor-infiltrating lymphocytes modified by retroviral gene transduction N Engl J Med 323(9) 570-578 https://doi. org/10.1056/NEJM199008303230904 PMID: 2381442

158.Ginn SL, Amaya AK, and Alexander IE, et al (2018) Gene therapy clinical trials worldwide to 2017: an update J Gene Med 20(5) e3015 https://doi.org/10.1002/jgm.3015 PMID: 29575374

159.Roth JA, Nguyen D, and Lawrence DD, et al (1996) Retrovirus-mediated wild-type p53 gene transfer to tumors of patients with lung cancer Nat Med 2(9) 985-991 https://doi.org/10.1038/nm0996-985 PMID: 8782455

160.Griffith TST, Stokes B, and Kucaba TA, et al (2009) TRAIL gene therapy: from preclinical development to clinical application Curr Gene Ther 9(1) 9-19 https://doi.org/10.2174/156652309787354612 PMID: 19275567 PMCID: 2727705 
161.Freeman SM, Abboud C, and Freeman SM, et al (1993) The "bystander effect": tumor regression when a fraction of the tumor mass is genetically modified Cancer Res 53(21) 5274-5283 PMID: 8221662

162.Nasu Y, Saika T, and Ebara S, et al (2007) Suicide gene therapy with adenoviral delivery of HSV-tK gene for patients with local recurrence of prostate cancer after hormonal therapy Mol Ther 15(4) 834-840 https://doi.org/10.1038/sj.mt.6300096 PMID: 17327829

163.Natsume A and Yoshida J (2008) Gene therapy for high-grade glioma: current approaches and future directions Cell Adh Migr 2(3) 186-191 https://doi.org/10.4161/cam.2.3.6278

164. Westphal M, Ylä-Herttuala S, and Martin J, et al (2013) Adenovirus-mediated gene therapy with sitimagene ceradenovec followed by intravenous ganciclovir for patients with operable high-grade glioma (ASPECT): a randomised, open-label, phase 3 trial Lancet Oncol 14(9) 823-833 https://doi.org/10.1016/S1470-2045(13)70274-2 PMID: 23850491

165.Ahrendt SA, Hu Y, and Buta M, et al (2003) p53 mutations and survival in stage I non-small-cell lung cancer: Results of a prospective study J Natl Cancer Inst 95(13) 961-970 https://doi.org/10.1093/jnci/95.13.961 PMID: 12837832

166. Raty J, Pikkarainen J, and Wirth T, et al (2010) Gene therapy: the first approved gene-based medicines, molecular mechanisms and clinical indications Curr Mol Pharmacol 1(1) 13-23 https://doi.org/10.2174/1874467210801010013

167.Elbashir SM, Harborth J, and Lendeckel W, et al (2001) Duplexes of 21-nucleotide RNAs mediate RNA interference in cultured mammalian cells Nature 411(6836) 494-498 https://doi.org/10.1038/35078107 PMID: 11373684

168. Weiss B, Davidkova G, and Zhou LW (1999) Antisense RNA gene therapy for studying and modulating biological processes Cell Mol Life Sci 55(3) 334-358 https://doi.org/10.1007/s000180050296 PMID: 10228554

169.Whelan J (2005) First clinical data on RNAi Drug Discov Today 10(15) 1014-1015 https://doi.org/10.1016/S1359-6446(05)03547-6 PMID: 16055013

170.Jia LT, Chen SY, and Yang AG (2012) Cancer gene therapy targeting cellular apoptosis machinery Cancer Treat Rev 38(7) 868-876 https:// doi.org/10.1016/j.ctrv.2012.06.008 PMID: 22800735

171.Putney SD, Brown J, and Cucco C, et al (1999) Enhanced anti-tumor effects with microencapsulated c-myc antisense oligonucleotide Antisense Nucleic Acid Drug Dev 9(5) 451-458 https://doi.org/10.1089/oli.1.1999.9.451 PMID: 10555152

172.Vita M and Henriksson M (2006) The Myc oncoprotein as a therapeutic target for human cancer Semin Cancer Biol 16(4) 318-330 https://doi.org/10.1016/j.semcancer.2006.07.015 PMID: 16934487

173.Fleming JB (2005) Molecular consequences of silencing mutant k-ras in pancreatic cancer cells: justification for k-ras-directed therapy Mol Cancer Res 3(7) 413-423 https://doi.org/10.1158/1541-7786.MCR-04-0206 PMID: 16046552

174.Scanlon K (2005) Anti-genes: sirna, ribozymes and antisense Curr Pharm Biotechnol 5(5) 415-420 https://doi.org/10.2174/ 1389201043376689

175.Fire AZ (2007) Gene silencing by double-stranded RNA Cell Death Differ 14(12) 19982012 https://doi.org/10.1038/sj.cdd.4402253 PMID: 18007671

176.Bora RS, Gupta D, and Mukkur TKS, et al (2012) RNA interference therapeutics for cancer: challenges and opportunities (review) Mol Med Rep 6(1) 9-15 PMID: 22576734

177.Van De Water FM, Boerman OC, and Wouterse AC, et al (2006) Intravenously administered short interfering RNA accumulates in the kidney and selectively suppresses gene function in renal proximal tubules Drug Metab Dispos 34(8) 1393-1397 https://doi.org/10.1124/ dmd.106.009555 PMID: 16714375

178.Jackson AL and Linsley PS (2010) Recognizing and avoiding siRNA off-target effects for target identification and therapeutic application Nat Rev Drug Discov 9(1) 57-67 https://doi.org/10.1038/nrd3010 PMID: 20043028 
179.Hornung V, Guenthner-Biller M, and Bourquin C, et al (2005) Sequence-specific potent induction of IFN-a by short interfering RNA in plasmacytoid dendritic cells through TLR7 Nat Med 11(3) 263-270 https://doi.org/10.1038/nm1191 PMID: 15723075

180.Judge AD, Sood V, and Shaw JR, et al (2005) Sequence-dependent stimulation of the mammalian innate immune response by synthetic siRNA Nat Biotechnol 23(4) 457-462 https://doi.org/10.1038/nbt1081 PMID: 15778705

181.Martina MS, Nicolas V, and Wilhelm C, et al (2007) The in vitro kinetics of the interactions between PEG-ylated magnetic-fluid-loaded liposomes and macrophages Biomaterials 28(28) 4143-4153 https://doi.org/10.1016/j.biomaterials.2007.05.025 PMID: 17574668

182. Whitehead KA, Langer R, and Anderson DG (2009) Knocking down barriers: advances in siRNA delivery Nat Rev Drug Discov 8(2) 129-138 https://doi.org/10.1038/nrd2742 PMID: 19180106

183.Xu C fei and Wang J (2015) Delivery systems for siRNA drug development in cancer therapy Asian J Pharm Sci 10(1) 1-12 https://doi. org/10.1016/j.ajps.2014.08.011

184.Czauderna F, Fechtner M, and Dames S, et al (2003) Structural variations and stabilising modifications of synthetic siRNAs in mammalian cells Nucleic Acids Res 31(11) 2705-2716 https://doi.org/10.1093/nar/gkg393 PMID: 12771196 PMCID: 156727

185.Liao H and Wang JH (2005) Biomembrane-permeable and ribonuclease-resistant siRNA with enhanced activity Oligonucleotides 15(3) 196-205 https://doi.org/10.1089/oli.2005.15.196 PMID: 16201907

186. Hall AHS, Wan J, and Shaughnessy EE, et al (2004) RNA interference using boranophosphate siRNAs: structure-activity relationships Nucleic Acids Res 32(20) 5991-6000 https://doi.org/10.1093/nar/gkh936 PMID: 15545637 PMCID: 534620

187.Elouahabi A and Ruysschaert JM (2005) Formation and intracellular trafficking of lipoplexes and polyplexes Mol Ther 11(3) 336-347 https://doi.org/10.1016/j.ymthe.2004.12.006 PMID: 15727930

188.Sarisozen C, Salzano G, and Torchilin VP (2015) Recent advances in siRNA delivery Biomol Concepts 6(5-6) 321-341 https://doi. org/10.1515/bmc-2015-0019 PMID: 26609865

189. Kim HS, Song IH, and Kim JC, et al (2006) In vitro and in vivo gene-transferring characteristics of novel cationic lipids, DMKD (O,O'dimyristyl-N-lysyl aspartate) and DMKE (O,O'-dimyristyl-N-lysyl glutamate) J Control Release 115(2) 234-241 https://doi.org/10.1016/j. jconrel.2006.08.003 PMID: 16989919

190. Kenny GD, Kamaly N, and Kalber TL, et al (2011) Novel multifunctional nanoparticle mediates siRNA tumour delivery, visualisation and therapeutic tumour reduction in vivo J Control Release 149(2) 111-116 https://doi.org/10.1016/j.jconrel.2010.09.020

191. Halder J, Kamat AA, and Landen CN, et al (2006) Focal adhesion kinase targeting using in vivo short interfering RNA delivery in neutral liposomes for ovarian carcinoma therapy Clin Cancer Res 12(16) 4916-4924 https://doi.org/10.1158/1078-0432.CCR-06-0021 PMID: 16914580 PMCID: 3144499

192.Gray MJ, Van Buren G, and Dallas NA, et al (2008) Therapeutic targeting of neuropilin-2 on colorectal carcinoma cells implanted in the murine liver J Natl Cancer Inst 100(2) 109-120 https://doi.org/10.1093/jnci/djm279 PMID: 18182619

193.ClinicalTrials.gov. US National Library of Medicine [https://clinicaltrials.gov/ct2/show/NCT01591356] Date accessed: 15/05/19

194.Soutschek J, Akinc A, and Bramlage B, et al (2004) Therapeutic silencing of an endogenous gene by systemic administration of modified siRNAs Nature 432(7014) 173-178 https://doi.org/10.1038/nature03121 PMID: 15538359

195.Rossi J (2006) RNAi therapeutics: SNALPing siRNAs in vivo Gene Ther 13(7) 583-584 https://doi.org/10.1038/sj.gt.3302661

196.ClinicalTrials.gov. US National Library of Medicine [https://clinicaltrials.gov/ct2/show/NCT00882180] Date accessed: 15/05/19

197.ClinicalTrials.gov. US National Library of Medicine [https://clinicaltrials.gov/ct2/show/NCT01262235] Date accessed: 15/05/19

198. Mao S, Sun W, and Kissel T (2010) Chitosan-based formulations for delivery of DNA and siRNA Adv Drug Deliv Rev 62(1) 12-27 https:// doi.org/10.1016/j.addr.2009.08.004 
199.Pillé J-YY, Li H, and Blot E, et al (2006) Intravenous delivery of anti-RhoA small interfering RNA loaded in nanoparticles of chitosan in mice: safety and efficacy in xenografted aggressive breast cancer Hum Gene Ther 17(10) 1019-1026 https://doi.org/10.1089/ hum.2006.17.1019 PMID: 17007568

200.ClinicalTrials.gov. US National Library of Medicine [https://clinicaltrials.gov/ct2/show/NCT00689065] Date accessed: 15/05/19

201.Urban-Klein B, Werth S, and Abuharbeid S, et al (2005) RNAi-mediated gene-targeting through systemic application of polyethylenimine (PEI)-complexed siRNA in vivo Gene Ther 12(5) 461-466 https://doi.org/10.1038/sj.gt.3302425

202.ClinicalTrials.gov. US National Library of Medicine [https://clinicaltrials.gov/ct2/show/NCT01676259] Date accessed: 15/05/19

203.Jeong JH, Mok H, and Oh YK, et al (2009) SiRNA conjugate delivery systems Bioconjug Chem 20(1) 5-14 https://doi.org/10.1021/ bc800278e

204.McNamara JO, Andrechek ER, and Wang Y, et al (2006) Cell type-specific delivery of siRNAs with aptamer-siRNA chimeras Nat Biotechnol 24(8) 1005-1015 https://doi.org/10.1038/nbt1223 PMID: 16823371

205. Gallas A, Alexander C, and Davies MC, et al (2013) Chemistry and formulations for siRNA therapeutics Chem Soc Rev 42(20) 7983-7997 https://doi.org/10.1039/c3cs35520a PMID: 23857524

206.Williford J-MM, Wu J, and Ren Y, et al (2014) Recent advances in nanoparticle-mediated sirna delivery Annu Rev Biomed Eng 16 347-370 https://doi.org/10.1146/annurev-bioeng-071813-105119 PMID: 24905873

207.Zhou J, Wu Y, and Wang C, et al (2016) pH-sensitive nanomicelles for high-efficiency sirna delivery in vitro and in vivo: an insight into the design of polycations with robust cytosolic release Nano Lett 16(11) 6916-6923 https://doi.org/10.1021/acs.nanolett.6b02915 PMID: 27748606

208.Sun CY, Shen S, and Xu CF, et al (2015) Tumor acidity-sensitive polymeric vector for active targeted sirna delivery J Am Chem Soc 137(48) 15217-15224 https://doi.org/10.1021/jacs.5b09602 PMID: 26571079

209.Truong NP, Gu W, and Prasadam I, et al (2013) An influenza virus-inspired polymer system for the timed release of siRNA Nat Commun 41902 https://doi.org/10.1038/ncomms2905 PMID: 23695696

210.Andreozzi P, Diamanti E, and Py-Daniel KR, et al (2017) Exploring the pH sensitivity of poly(allylamine) phosphate supramolecular nanocarriers for intracellular siRNA delivery ACS Appl Mater Interfaces 9(44) 38242-38254 https://doi.org/10.1021/acsami.7b11132 PMID: 29039643

211.van der Zee J (2002) Heating the patient: a promising approach? Ann Oncol 13(8), 1173-1184 https://doi.org/10.1093/annonc/mdf280 PMID: 12181239

212.Bruix J and Sherman M (2005) Management of hepatocellular carcinoma Hepatol 42(5) 1208-1236 https://doi.org/10.1002/hep.20933

213.Lencioni R and Crocetti L (2008) Image-guided thermal ablation of hepatocellular carcinoma Crit Rev Oncol Hematol 66(3) 200-207 https://doi.org/10.1016/j.critrevonc.2008.01.003 PMID: 18304832

214. Kudo M (2004) Local ablation therapy for hepatocellular carcinoma: current status and future perspectives J Gastroenterol 39(3) 205-214 https://doi.org/10.1007/s00535-003-1280-y PMID: 15064996

215. Brace CL (2009) Radiofrequency and microwave ablation of the liver, lung, kidney, and bone: what are the differences? Curr Probl Diagn Radiol 38(3) 135-143 https://doi.org/10.1067/j.cpradiol.2007.10.001 PMID: 19298912 PMCID: 2941203

216.Schramm W, Yang D, and Haemmerich D (2007) Contribution of direct heating, thermal conduction and perfusion during radiofrequency and microwave ablation Open Biomed Eng J 1 47-52 https://doi.org/10.2174/1874120700701010047 PMID: 19662127 PMCID: 2701080 
217.Sartori S, Tombesi P, and Di Vece F (2015) Radiofrequency, microwave, and laser ablation of liver tumors: time to move toward a tailored ablation technique? Hepatoma Res 1 52-57 https://doi.org/10.4103/2394-5079.155697

218.Schena E, Saccomandi P, and Fong Y (2017) Laser ablation for cancer: past, present and future J Funct Biomater 8(2) pii: E19 https://doi. org/10.3390/jfb8020019 PMID: 28613248 PMCID: $\underline{5492000}$

219. Izzo F (2003) Other thermal ablation techniques: microwave and interstitial laser ablation of liver tumors Ann Surg Oncol 10(5) 491-497 https://doi.org/10.1245/ASO.2003.07.016

220.Giorgio A, Tarantino L, and De Stefano G, et al (2000) Interstitial laser photocoagulation under ultrasound guidance of liver tumors: Results in 104 treated patients Eur J Ultrasound 11(3) 181-188 https://doi.org/10.1016/S0929-8266(00)00086-0 PMID: 10874193

221.Francica G, lodice G, and Delle Cave M, et al (2007) Factors predicting complete necrosis rate after ultrasound-guided percutaneous laser thermoablation of small hepatocellular carcinoma tumors in cirrhotic patients: A multivariate analysis Acta Radio 48(5) 514-519 https://doi.org/10.1080/02841850701199942

222.Puls R, Langner S, and Rosenberg C, et al (2009) Laser ablation of liver metastases from colorectal cancer with MR thermometry: 5-year survival J Vasc Interv Radiol 20(2) 225-234 https://doi.org/10.1016/j.jvir.2008.10.018

223.Dennis CL and Ivkov R (2013) Physics of heat generation using magnetic nanoparticles for hyperthermia Int J Hyperthermia 29(8) 715-729 https://doi.org/10.3109/02656736.2013.836758 PMID: 24131317

224.Giustini AJ, Petryk AA, and Cassim SM, et al (2010) Magnetic nanoparticle hyperthermia in cancer treatment Nano Life 1(1n02) https:// doi.org/10.1142/S1793984410000067 PMID: 24348868 PMCID: 3859910

225.Society of Radiographers (2013) A guide to modern radiotherapy ISBN: 1-871101-94-8

226.Gogvadze V, Orrenius S, and Zhivotovsky B (2008) Mitochondria in cancer cells: what is so special about them? Trends Cell Biol 18(4) 165-173 https://doi.org/10.1016/j.tcb.2008.01.006 PMID: 18296052

227.Lynam-Lennon N, Maher SG, and Maguire A, et al (2014) Altered mitochondrial function and energy metabolism is associated with a radioresistant phenotype in oesophageal adenocarcinoma PLoS One 9(6) e100738 https://doi.org/10.1371/journal.pone.0100738 PMID: 24968221 PMCID: $\underline{4072695}$

228. Liao X, Chaudhary P, and Qiu G, et al (2018) The role of propranolol as a radiosensitizer in gastric cancer treatment Drug Des Devel Ther 12 639-645 https://doi.org/10.2147/DDDT.S160865 PMID: 29636598 PMCID: 5880513

229.Collins FS and Varmus H (2015) A new initiative on precision medicine N Engl J Med 372(9) 793-795 https://doi.org/10.1056/ NEJMp1500523 PMID: 25635347 PMCID: 5101938

230.Gutman DA, Cooper LAD, and Hwang SN, et al (2013) MR imaging predictors of molecular profile and survival: multi-institutional study of the tcga glioblastoma data set Radiol 267(2) 560-569 https://doi.org/10.1148/radiol.13120118

231.Lambin P, Rios-Velazquez E, and Leijenaar R, et al (2012) Radiomics: extracting more information from medical images using advanced feature analysis Eur J Cancer 48(4) 441-446 https://doi.org/10.1016/j.ejca.2011.11.036 PMID: 22257792 PMCID: 4533986

232. Fuchs TJ and Buhmann JM (2011) Computational pathology: challenges and promises for tissue analysis Comput Med Imaging and Graph 35(7) 515-530 https://doi.org/10.1016/j.compmedimag.2011.02.006

233.Foran DJ, Yang L, and Chen W, et al (2011) ImageMiner: A software system for comparative analysis of tissue microarrays using content-based image retrieval, high-performance computing, and grid technology J Am Med Informa Assoc 18(4) 403-415 https://doi. org/10.1136/amiajnl-2011-000170

234.Clarke LP, Croft BS, and Nordstrom R, et al (2014) Quantitative imaging for evaluation of response to cancer therapy Transl Oncol 2(4) 195-197 https://doi.org/10.1593/tlo.09217 
235.Cooper LAD, Kong J, and Gutman DA, et al (2012) Integrated morphologic analysis for the identification and characterization of disease subtypes J Am Med Inform Assoc 19(2) 317-323 https://doi.org/10.1136/amiajnl-2011-000700 PMID: 22278382 PMCID: 3277636

236. Romo-Bucheli D, Janowczyk A, and Gilmore H, et al (2016) Automated tubule nuclei quantification and correlation with oncotype dx risk categories in ER+ breast cancer whole slide images Sci Rep 632706 https://doi.org/10.1038/srep32706 PMID: 27599752 PMCID: 5013328

237.Lewis JS, Ali S, and Luo J, et al (2014) A quantitative histomorphometric classifier (QuHbIC) identifies aggressive versus indolent p16-positive oropharyngeal squamous cell carcinoma Am J Surg Pathol 38(1) 128-137 https://doi.org/10.1097/PAS.0000000000000086

238.Kalpathy-Cramer J, Freymann JB, and Kirby JS, et al (2014) Quantitative imaging network: data sharing and competitive algorithmvalidation leveraging the cancer imaging archive Transl Oncol 7(1) 147-152 https://doi.org/10.1593/tlo.13862 PMID: 24772218 PMCID: 3998686

239.Schlett CL, Hendel T, and Weckbach S, et al (2016) Population-based imaging and radiomics: rationale and perspective of the german national cohort MRI study RoFo 188(7) 652-661 https://doi.org/10.1055/s-0042-104510 PMID: 27139177

240.ClinicalTrials.gov. US National Library of Medicine [https://clinicaltrials.gov/ct2/results?cond=\&term=radiomics\&cntry=\&state $=\& c i t y=$ \&dist=] Date accessed: 15/05/19 